\title{
Analysis of Factors Giving the Opportunity for Implementation of Innovations on the Example of Manufacturing Enterprises in the Silesian Province
}

\author{
Henryk Wojtaszek ${ }^{1}$ and Ireneusz Miciuła ${ }^{2, *(D)}$ \\ 1 Faculty of Management and Command, War Studies University, 00-910 Warsaw, Poland; \\ h.wojtaszek@akademia.mil.pl \\ 2 Faculty of Economics, Finance and Management, University of Szczecin, 70-453 Szczecin, Poland \\ * Correspondence: ireneusz.miciula@usz.edu.pl
}

Received: 29 August 2019; Accepted: 19 October 2019; Published: 22 October 2019

check for updates

\begin{abstract}
This paper analyzes the actions that improve innovativeness in production enterprises in the Silesian province. Innovation is one of the elements that allows to achieve a competitive advantage. It is justified to research various factors that are important in improving innovativeness. The research includes selected production enterprises in the Silesian province, adopting the descriptive statistics measures and statistic tests: random sample test, chi-square independence test and the non-parametric Kruskal-Wallis test based on a survey questionnaire. Some of the most important factors determining the possibilities of innovation by manufacturing companies were detected contacts with other enterprises, $R \& D$ centers and counseling institutions, competitive position of the company, and creating appropriate incentive systems.
\end{abstract}

Keywords: innovation; innovative activities; analysis of factors; production enterprises

\section{Introduction}

To improve and streamline the management of companies in recent years, innovations should be introduced which cause a demand, enhance the pace of development of enterprises, and reduce the prices of products that meet the ever-growing human needs. A lot of research in this field indicates that innovations are strongly associated with increasing the efficiency or competitive position of the company on the market [1]. Therefore, the ability to create and absorb innovation are the fundamental challenges of the $21^{\text {st }}$ century. Analysis and assessment of enterprises' innovativeness is complicated and often raises numerous doubts [2]. Innovation is the result of a number of factors both inside the company and outside its environment [3]. Factors such as: microenvironment, environmental diversity, scale, structure, strategies, enterprises, entrepreneurial aspirations, and their creativity and propensity to take risks related to innovative activities play a significant role here. The research effort and modernity of the implemented solutions as conditions for its innovation are also emphasized. The nature of innovative processes is a complex issue, and therefore, proposing an exact set of conditions that would define and determine the propensity of enterprises to create such solutions is difficult to implement [4]. That is why so much research is being done on this topic. It is also our motivation for research in this area, where the current development of the surveyed enterprises in a given country and specific geographical space is also important. Therefore, the analysis of many research works may allow to determine the universal determinants of innovative activities carried out by basic business units, i.e., enterprises. Important factors conditioning the achievement of innovative success are also: independence of thinking, ability to critically assess reality, and readiness to take risks. It should also be emphasized that every innovation is a change, but at the same time not every change is an innovation. It can also be a non-creative transformation or duplication of existing solutions. 
The research objective was to conduct an analysis in terms of innovative actions undertaken by production enterprises in the Silesian province. These were small, medium and large enterprises. The survey questionnaires included questions allowing to obtain information about:

(1) the age of the enterprise, its size and range of activities;

(2) types of innovations introduced by the enterprises and barriers to implementation;

(3) evaluation of the innovation levels when compared to the competition, according to the respondents;

(4) having an innovation unit responsible for implementation of innovations; and

(5) employing the measures that help in implementing the innovations.

As part of the contribution from the study, some universal factors that influence the innovativeness of enterprises on a global scale were confirmed. The vast majority of the surveyed production enterprises showed, as the determinants of the rare introduction of innovation, that there is a lack of financial capital for development, outdated technology, and a lack of qualified employees. In addition, the main barriers identified did not depend on the age of the companies. At the same time, the presented study introduces to the discussed issues a number of conclusions regarding enterprises at a given level of state development, and thus, external factors affecting the conducted economic activity. For example, in the examined Silesian region, the success of an enterprise depends on the competitive advantage that results from the type of introduced innovations. This is because the longest operating companies on the market were those that introduced process innovations. Therefore, the following research is making a new analytical contribution to innovation factors.

\section{Literature Review}

Innovation is the transformation of ideas and creativity into useful goods, services or technologies [5]. It includes research, organisational, financial and marketing activities. Innovation plays a different role in every stage of a company's life cycle. An innovation-oriented company has the ability to transform an original concept into a useful result, stimulate employees' creativity and face competition [6].

Innovation is the ability to create something new, i.e., it is the way to make creative ideas come true and put them into practice. Innovation takes place through the implementation of a new or significantly improved product, service or production process, including the initiation of new marketing activities and organizational changes, resulting in a different approach to work and relationships between the enterprise and the external environment [7]. A new solution is an innovation only when it is applied in a company's activity. Innovation leads to increased efficiency and thus to increased competitiveness of the company in the market [8]. A technological innovation occurs when a new or improved product is launched on the market or when a modern or improved production process is used. The company acquires new technology from its owner or modernises its own. New possibilities for the use of existing products are also being explored. Modern technology is an important tool for competition, as it enables the introduction of new and modified products and the improvement of marketing activities [9].

Development of J.A. Schumpeter in the scope of cyclical economic development is a concept of long waves and cycles of industrial evolution from the beginning of the 20th century by the Russian economist N.D. Kondratieva (1935), who presented the progressive evolution of industry in the form of four long waves associated with a change in the techno-economic paradigm. In this concept, changes that have been taking place in the economic system since the end of the 18th century were caused by the introduction of groundbreaking innovations. Many researchers are now returning to this concept, and its revitalization is associated with the conclusion, in addition to economic elements and spatial elements. Interest of the research group for the concept of long waves N.D. Kondratieva, including such as: N. Rosenberg and C. Frischtak (1984), Ch. Freeman and C. Perez (1988), A. Grübler and H. Nowotny (1990), R. Hayter (1997), P. Dicken (1998), T. Stryjakiewicz (1999), P. Haggett (2001), results from the regularities she describes, which are also of a spatial nature and are mainly manifested in 
the form of the location of the place where the breakthrough innovation appeared [10]. Another concept, which is an extension of Schumpeter's considerations related to the cyclicality of economic development, is the theory of G. Mensch (1979), who studied the model of cycles of structural changes, assuming that the economy developed in the form of a series of intermittent innovation impulses in the form of consecutive S-shaped cycles. G. Mensch also drew attention to the group occurrence of breakthrough innovations, and his concept is an important theoretical contribution to research on the issue of innovation.

The other theory is Porter's cluster theory. The cluster is called "located in a geographical neighborhood a group of enterprises and related institutions dealing with a specific field, connected by similarities and complementary each other" (Porter 2001) [11]. The geographical range of the bunch is not clearly defined. It may include one city, region, country or group of neighboring countries. Clusters, by offering investors many benefits, can count on synergy. Innovation in location theory can also be considered in the context of the concept of spatial self-organization, which is a "tool for explaining the spatial system of the economy" (Budner 2003). This theory illustrates how complex systems move from one order to another if the assumption that the systems being tested are open, non-linear, and far from equilibrated is met. From the theory of physics to economics, a description of how to change from one order to another was transferred (Domański 1997). An imbalance in physics is a differentiation and in economics that leads to differences in the functioning of areas (cities, regions), e.g., to a different employment structure or investment outlays. Non-linearity can be compared to economies of scale and perturbations are compared to the effects of introduction new technologies, which result in innovation and development impulses. We are dealing with fluctuations when as a result of impulses there are changes in the behavior of people, enterprises and institutions. Interactions between elements of economic systems in space are observed - changes in relationships.

Analyzing the presence of innovations in social life, it is easy to see that this term refers not only to inventions introduced in the technical and technological sphere, but also to solutions having an organizational and marketing nature, and finally to creating social institutions whose purpose is to support innovative processes in organizations. Peter Drucker saw innovation as a special tool that helps entrepreneurs regardless of their business. Thanks to it, changes create an opportunity for companies to meet new challenges in the economic sphere. The modern definition of innovation is presented in the Oslo Manual. Its authors write that we are dealing with the implementation of a new or significantly improved product or service on the market, process, marketing method or work organization. Peter Drucker highlighted seven opportunities to create innovation. In his opinion, four are taking place inside the company, namely: sudden success or failure in the market, coming to the collision of reality with ideas about it, the emergence of innovation resulting from the need for the process, and changes taking place in the structure of the market or industry [12].

Innovation can be stimulated by changing the organisational structure, removing constraints, flexible action, and the use of stimuli of material interest [13]. Employees must have easy access to the resources necessary to implement innovation (e.g., purchase of new technology, coverage of costs) and the information system, and the risk of failure is tolerated. Some barriers to innovation break down efficient Internet and intranet communication. In order to implement innovations, inter-departmental functional teams and task forces (product development, problem solving and organisation improvement) are often established. Innovation is fostered by a high culture of work that encourages experimentation, rewards for success and neutralisation of the risk of failure [14].

Innovations that deliver new value to customers are typically manifested in new products, technologies, ideas, approaches, and systems that should generate benefits primarily for customers who, by being attached to companies on the basis of their positive experiences, will guarantee high profitability of the company [15]. With the development of the service sector, the scope of innovation has expanded significantly and has gone beyond the technical sphere. Innovations have begun to be treated in a broad sense as a good, a service or an idea, perceived by someone as new [16]. In view of the success of both individual economic entities and the economies of the most competitive countries in the world, 
we should strive for similar innovative activity [17]. The Polish economy should become innovative, thanks to which in the future its competitive position and economic condition on the international arena could be significantly strengthened and improved. In an innovative enterprise, the management should understand that there is no single best way to succeed in innovation management [18]. It should be remembered that innovation is only fully successful if its management is supported by the entire organisation. Success in innovation management is based on an organisation's ability to learn and repeat similar behaviours. It depends on the effective links between the strengths and weaknesses of the company and its environment [19]. The state should support innovative activities of Polish enterprises through the use of appropriate instruments. The group of instruments that affect the entire research process includes: government grants and subsidies, agreements, and programme contracts [20,21].

On the other hand, different types of financial services are among the instruments that only affect specific elements of the research process. To gain an effective competitive advantage, businesses should try to stay ahead of the competition in finding what's innovative and difficult to copy. Only companies that systematically strengthen their competitive position will be able to survive on the market. Competitive advantage can be gained mainly through continuous improvement of the level of innovation, and thus, obtaining appropriate efficiency. Companies should create a creative management team within their own system and adopt a policy that will create a climate of innovation. Managers of organizations should therefore show creative inventiveness and creativity. However, it should be remembered that not only managers must understand the essence of implementing innovation in the company. Therefore, employees should be able to see and solve unusual problems, be able to work in groups, not be afraid of challenges, and be open to the opinions and evaluations of others and prepared to act in conflict situations. Employees' predispositions should be developed through various training courses, facilitating contacts with specialists, research and development centres or universities. It is also important to move away from a hierarchical structure and give workers more freedom to make decisions. One of the main determinants of undertaking innovative undertakings by enterprises is their management of research and development activity [13]. In Poland, however, the outlays incurred for this purpose are definitely too low. The demotivating factor of undertaking innovative activity by Polish companies is their pessimism related to the implementation of innovations and the effects they will bring in the future. In recent years, a significant role in the transfer of new technologies in Poland has been played by foreign direct investments, which are more and more often treated as an element of the strategy of enterprises seeing opportunities for development in expansion on the global market. The reasons for low innovative activity of Polish enterprises include also the lack of cooperation with the scientific environment, e.g., with universities, which may give the possibility of practical application of the developed innovative solutions [22].

The competitiveness of enterprises is conditioned by many external and internal factors. The first group of factors includes e.g., the policy of the state and other institutions closely related to the functioning of enterprises, the condition of material and intellectual infrastructure, and relations with contractors and competitors. Other elements of incentives include management method, working capital, modern techniques and technologies, and quality of manufactured products. There are also various classifications of conditions for innovative activity in enterprises [1,23].

Improvement of innovative skills of the staff is achieved by promoting the benefits of training and improving qualifications by employees, spreading knowledge and inspiring employees to update it on an ongoing basis. Employees with creative mindsets are provided with secure employment to reduce fear of dismissal if they make mistakes when innovating. In this way, a group of workers emerges who are becoming advocates of progress. The avant-garde of innovation is characterized by self-confidence, perseverance, energy and a tendency to take risks. Innovations are fostered by darts and competent management, creating a fertile ground to inspire and promote the vision and strategy of the company's development. This results in a strong motivation for employees to take initiatives that deserve recognition. Freedom of conduct helps employees to adapt to innovative solutions. The innovation process is characterised not only by triggering initiatives and consolidating 
positive actions, but also by perceiving the stress associated with them and determining ways to alleviate them. A new or existing company needs to determine which market it wants to enter and how to stay there. Competitive ability manifests itself in offering better quality products and higher efficiency and effectiveness of marketing activities. An enterprise may gain a competitive advantage over other enterprises by increasing its production potential, having special resources, in particular human capital, and seeking the favour of buyers [24].

Innovative projects are therefore an important tool for competition. Depending on the chosen strategy, the company obtains or loses opportunities for activity in a given industrial sector and creates foundations to survive and to maximize profit. However, strategies that are conducive to maximising the profit of a company are not always good for society as a whole. Although factors of production are important to gain competitive advantage, the company's development strategy is becoming more and more important. Determining what it wants to do better and how it wants to do it is also a starting point for achieving a competitive advantage. The organizational structure should be designed in such a way that it is conducive to competition, and the way of competition is thoughtful and effective. It is necessary to identify the factors determining demand on a local, regional, national, and international scale. The existence of related industrial and service sectors in the country supports innovation and competitiveness. By competing domestically for innovation and product quality, companies gain important skills and experience that also give them the advantage to compete abroad. Nissan, Toyota and Honda compete successfully on the world market, but above all they try to be competitive on the Japanese market. International trade has a positive impact on the development of innovation, as it leads to higher product quality, lower costs and higher productivity. However, it shortens the time of reaction to phenomena favouring or limiting innovative undertakings. Import restrictions, high administrative fees for imported products, and burdensome border controls are a prerequisite for the competitiveness of these companies $[15,16]$.

An innovation-oriented enterprise should be able to search for new solutions, ideas and concepts of business development. Creative ideas and inventions are transformed into useful goods, services or modern technologies. Creativity, the ability to seize opportunities, taking risks, and adapting to the external environment are of fundamental importance in the innovation process. Innovation results from fierce competition on the market, continuous improvement of product quality, strong fluctuations in demand, and the needs and preferences of buyers [25]. Challenges for enterprises are related to the expectation of benefits from innovative undertakings, related to accepting and throwing challenges to competitors.

The innovativeness of the country's economy depends on a number of factors determining the scope and level of its operation. The main factors of innovativeness and competitiveness of the enterprise are: the ability to invent, create and undertake innovations; the ability to absorb innovations; structural abilities to strengthen the competitive position, i.e., the potential to increase the market share based on the technical and organisational structure; competence to develop product innovation and assortment on the basis of the possessed technical, technological and financial potential; and innovative abilities of the technical and technological potential, meaning the degree of attractiveness and innovativeness of the possessed technique and technology. Enterprises aiming at maintaining a constant competitive advantage are forced to improve their operations and take actions aimed at its improvement. This can be achieved by conducting innovative activity, which is aimed at the implementation of development objectives of the company, as well as promotes the emergence of new areas and sectors of economic activity.

Today's companies should be innovative organisations, but innovative companies may be considered to be companies that carry out extensive research and development or use the results of such as work outside the company. It allocates relatively large financial outlays to this activity. It systematically implements new scientific and technical solutions. It has a large share of novelties in the production or services provided. It systematically creates innovations and introduces them to production, work organisation and the market [21,26]. 
Innovative Activity in Poland

Innovations are often associated with progress and modernity, and their diffusion into the sphere of practical functioning contributes to a large extent to the development of economic entities. They are the most important driving force behind business development, as they are specific entrepreneurial tools. Entrepreneurship, which is expressed in the constant search for new concepts of production factors, is the engine of technical progress.

The innovativeness of the Polish industry has been recently limited by many factors: accumulation and demand barrier, competitive import pressure, high innovative risk, shortage of qualified personnel, conservative policy of strategic investors, instability of economic and financial regulators, and poor financial conditions of recipients with still significant demands for traditional goods. Barriers to innovation within Polish enterprises, as well as in their surroundings, indicate the necessity to conduct an appropriately oriented economic policy, an especially industrial and pro-innovative one. With regard to companies seeking and implementing innovation, there are obstacles to innovation: too high interest rates on loans, lack of own financial resources, lack of development base, high degree of market uncertainty, legal acts, standards and regulations, lack of recognition of market needs, lack of information on technology, and lack of cooperation with other institutions. Competition policy implemented by the state is of particular importance in supporting innovative activity, which, as a result, is a way to increase the competitiveness of enterprises. It aims, among other things, at promoting innovation by financing the research and development sphere of enterprises and technological and innovative development through supporting pro-innovative institutions.

Between 2012 and 2014, 18.6\% of industrial enterprises and 12.3\% of service sector enterprises (compared with $18.4 \%$ and $12.8 \%$ in $2011-2013$ ) showed innovative activity. New or significantly improved product innovations were introduced by $17.5 \%$ of industrial enterprises and $11.4 \%$ of service sector enterprises (2011-2013) [27]. Within product innovations, new or significantly improved products were introduced by $10.7 \%$ of industrial enterprises, while services were introduced by $4.7 \%$ of enterprises from the service sector. Among process innovations, industrial enterprises most often implemented new methods of manufacturing goods and services $(10.0 \%)$, and entities in the service sector implemented new methods supporting processes in enterprises (6.1\%). Among organisational innovations, industrial enterprises most often introduced new organisational procedures $(6.2 \%)$, while entities in the service sector most often introduced new methods of division of tasks and decision-making powers (7.3\%). From marketing innovations in industry, most enterprises introduced changes in the design/construction or packaging of goods or services $(4.4 \%)$, and in the service sector, most enterprises introduced changes in new media or product promotion techniques (5.4\%).

Taking into account the size of the surveyed enterprises, the share of enterprises that introduced innovations in the total number of enterprises is the highest in entities employing 250 people and more. The reason for this situation is, above all, better access to financial resources by these economic operators. Both industry and services were dominated by companies introducing process innovations ( $45.0 \%$ and $36.3 \%$ respectively). The smallest number of innovations introduced to the market can be observed in enterprises employing 10-49 persons and these are marketing innovations, which are $5.4 \%$ in industrial enterprises and $6.7 \%$ in enterprises from the service sector. Innovative activity of enterprises is often very specific, and its analysis is extremely difficult. This is linked, among other things, to the difficulty of defining this concept, as well as to the creative characteristics of innovation. This concept is directly connected with actions aimed at implementing changes that are to lead to an increase in the modernity and competitiveness of the organisation and, as a result, to an increase in its value.

The main goal motivating enterprises to implement innovations is economic and social in nature, and it is usually striving to ensure appropriate conditions for the implementation of a long-term strategy of development of the organization, which in turn is to lead to the satisfaction of customer needs. An entrepreneur should always and constantly seek for changes, as well as react to them and use them as a good opportunity. Enterprises that cannot create and use innovations will not stay in 
the market, while those that want to develop must remain open to changes, as well as create and introduce new innovations. The approach to innovation and the way it is created in enterprises is systematically changing. These changes are directly related to the emergence of new concepts and methods, covering more and more comprehensively the process of creating innovations at the level of production and service units. New trends in innovation concern both the process of creating products and services as well as changes taking place in the company's structure. Research in the form of the report "Smart Industry Poland 2018" can also be indicated. This report is a continuation of research on the level of innovativeness resulting from the implementation of technology among micro, small and medium production enterprises conducting business activity in Poland [20]. The interest in this subject results from the assumption that the faster entrepreneurs are able to define the configuration of a wide range of various digital technologies in the face of the adopted market strategy, the easier it will be for them to respond to the expectations of customers in the near future [22]. The diagnosis of innovativeness of the Polish economy shows that Polish industry (with few exceptions) is de facto at the stage of the third industrial revolution. Considering the fact that Poles are perceived as a very enterprising nation, and digitalization has a universal dimension, it is puzzling to note the relatively low innovativeness of micro, small and medium enterprises, which constitute over $99 \%$ of companies in Poland. According to CSO data, innovative solutions are introduced in Poland by only a dozen or so percent of industrial enterprises (as well as service enterprises). Therefore, it becomes extremely important to search for the causes of this situation and, what is more important, to propose adequate solutions enabling support for entrepreneurs in improving their competitive advantages not only within the national sector in which they compete, but also on an international or global scale. It is also an important area for shifting the place of the Polish economy from the group of countries oriented towards effectiveness to the countries of the group oriented towards innovation [23]. Polish industrial enterprises are still dominated by product and process innovations. Modern enterprises, which want to be more innovative, and thus competitive, focus their activities equally strongly on service innovations. Such modernizations are mainly the result of continuous and intensified research and development works, which are unfortunately lacking in the majority of Polish enterprises. A significant part of financial resources allocated to innovative activity is inefficiently spent. The reason for such a situation is the mismatch between the actions undertaken and the existing barriers, as well as economic benefits, caution in financing innovative projects, and support by the public sector mainly for safe investment projects of large enterprises.

Compared to most EU countries, Poland is still at a fairly low level of innovation. The Sumary Innovation Index (SII) being the evaluation criterion, is about 300 points, while the EU average is around 450 points. Leading in innovation, such countries as: Sweden, Denmark, Finland, and Germany, achieve more than twice as high innovation rates compared to Poland. Therefore, the results obtained will be characteristic of enterprises operating in developing countries. At local and regional levels, regional innovation strategies, and in particular the reality of their implementation, are important instruments for increasing innovation. For the Śląkie Voivodeship, the Regional Innovation Strategy of the Ślaskie Voivodship for the years 2013-2020 has been developed, which is already the second document of this type in the region. The first innovation strategy was implemented in the years 2003-2012. The importance of this type of strategic development is associated with the effectiveness of achieving goals and the possibility of implementing broadly understood strategic initiatives. According to the report of the Polish Agency for Enterprise Development, in 2016-2018, 35.8\% of companies operating in Poland introduced at least one innovation of any type. In manufacturing enterprises, many activities related to the operation depend on the capital held. Due to the research area, more specifically the Silesian agglomeration, where there are many production plants, the purposeful presentation of process and product innovations was made. Product and process innovations are considered technological innovations. That is why the Silesian region was chosen as part of existing enterprises in Poland [19-21].

The authors present the latest research published by the Polish Agency for Enterprise Development. The report presents the results of the second edition of the cyclical survey conducted by the Polish 
Agency for Enterprise Development entitled "Monitoring of innovativeness of Polish enterprises", which aims to diagnose the state of innovativeness of Polish enterprises and factors shaping its level of innovativeness. The survey consists of an annual measurement of the level of innovativeness of enterprises by means of quantitative (CAPI) and qualitative (IDI) techniques. The target group of the survey are companies operating in Poland divided into four sizes according to the criterion of employment: micro, small, medium, and large.

As far as the scale of innovative activity of Polish companies is concerned, we can state that in 2016-2018, 35.8\% of companies operating in Poland were active innovatively. These companies have introduced or tried to apply at least one innovation in their business activity; $32.4 \%$ of companies can be described as innovative. These are companies that have introduced at least one innovation in this period. The percentage of innovative and actively innovative companies is significantly, positively correlated with the size of the company: the larger the company, the higher the percentage of companies classified as innovative or innovation active. Comparison of these results with the first edition shows a slight increase in the percentage of innovation active companies by 3.5 percentage points and innovative companies by 2.3 percentage points.

The authors note that in 2016-2018, companies were working on various types of innovations. Product innovations were worked on by $20.1 \%$, where they were introduced by $17.9 \%$ of the surveyed companies. Process innovations amounted to $19.4 \%$ and innovative ones to $16.3 \%$. For organisational innovations, the percentage of innovation active companies was $10 \%$, while for innovative ones, it was $7.4 \%$. On the other hand, $14.1 \%$ worked on marketing innovations, while they were introduced by $11.1 \%$. With regards to the type of expenditures on innovative activity conducted by enterprises in the years 2016-2018, the dominating ones were expenditures on investment in tangible assets through the purchase of machinery and equipment, including computer equipment, means of transport, tools, movables and equipment, as well as buildings ( $65 \%$ of the total number of innovation active companies). Next, innovation-active companies incurred expenditures on the purchase of staff trainings related to the introduction of new or significantly improved products and processes $(40 \%)$ and software related to the introduction of product and process innovations $(36 \%)$, also on the costs of marketing related to the introduction of new or significantly improved products $(22 \%)$. B+R works are the least frequently carried out forms of innovative activity in innovation-active companies, both in terms of $B+R$ works performed on their own (11\%) and those acquired from outside $(6 \%)$. Moreover, in order to conduct innovative activity, external sources of financing were used: bank credits, loans or leasing $(47 \%)$; EU funds (24\%); state budget funds (6\%); risk capital funds (2\%); and other than European funds funds resources obtained from abroad (2\%).The main source of innovation in Polish enterprises is the management staff ( $71 \%$ of all innovation active companies indicated this source), followed by the external environment of the company: customers, suppliers and competitors (63\% of all innovation active companies). These observations were confirmed in a qualitative study: Innovative activities in companies, regardless of the size of the company, are stimulated by the owner, the management board/managing director, and managers. The greater the outlays and resources required for innovation, the more obvious it is that the risk and decisions related to its implementation depend on the managers. In large companies, the presence and influence of creative employees and $\mathrm{B}+\mathrm{R}$ team on undertaking innovative activities is noticeable.

The authors move in the field of research of production companies in various provinces. Research is planned in all voivodships. Due to the limited nature of the article, the results of the research completed in the Silesian Voivodeship have been presented at the moment due to the access to these studies.

One of the key statements in the literature on the subject is the fact that innovation may depend on the competitive advantage responsible for the introduced changes aimed at increasing the company's profit or maximizing it.

The following working hypotheses were assumed:

(1) The type of implemented innovations depended on the size of the company 
(2) The type of innovation implemented depended on the scope of its activities

(3) The type of innovation introduced depended on the age of the innovation

(4) The employment size does not determine the type of implemented innovation.

(5) The range of company's activity determines the implementation of innovation [14].

(6) Having an innovation unit does not depend on the size of the company.

(7) The range of the company's activities significantly determined the fact of having an innovation unit [15].

(8) The type of implemented innovations depended on whether a company had an innovation unit.

(9) The reason for not implementing any innovations is lack of development capital [16].

(10) The barriers to growth faced by the surveyed enterprises depended on the size of the enterprises.

(11) The range of company's operations posed a significant determinant for the barriers to growth $[17,18]$.

\section{Materials and Methods}

The group of respondents was composed of owners of managers of the production enterprises as well as their employees. The subject of the research activities included production enterprises in the Silesian province. The research area covered the Silesian province. The research period was 2011-2016. A total of 310 production enterprises were surveyed in that time. The main limitation of the surveyed population was the cost and the time-consuming nature of the project. Statistical offices, town halls or country offices did not have any data on the actual status of active enterprises. The reasons for the lack information were:

no consistency in the provision of information by entrepreneurs, for example in relation to cessation of activities;

changing formats of reporting on economic operators;

intended fraudulent behaviors of entrepreneurs, e.g., operating on the grey market [3].

Data from the Central Statistical Office were regarded as the most reliable source of information in the Silesian province. The population data were generated from Central Statistical Office, which were updated on the basis of data from the Central Statistical Office in Katowice. Therefore, the population of production enterprises was composed of the enterprises classified by the Central Statistical Office in section C of the Classification of Economic Activities, namely "Industrial processing", including:

(1) Division 10: manufacture of food products;

(2) Division 11: manufacture of beverages

(3) Division 12: manufacture of tobacco products;

(4) Division 13: manufacture of textiles;

(5) Division 14: manufacture of wearing apparel;

(6) Division 15: manufacture of leather and related products;

(7) Division 16: manufacture of wood and of products of wood and cork, except furniture; manufacture of articles of straw and plaiting materials;

(8) Division 17: manufacture of paper and paper products;

(9) Division 20: manufacture of chemicals and chemical products;

(10) Division 21: manufacture of basic pharmaceutical products, medicines and pharmaceutical preparations;

(11) Division 22: manufacture of rubber and plastic products;

(12) Division 23: manufacture of other non-metallic mineral products;

(13) Division 24: manufacture of basic metals;

(14) Division 25: manufacture of fabricated metal products, except machinery and equipment;

(15) Division 26: manufacture of computers, electronic and optical products; 
(16) Division 27: manufacture of electrical equipment;

(17) Division 28: manufacture of machinery and equipment n.e.c;

(18) Division 29: manufacture of motor vehicles, trailers and semi-trailers, except for motorcycles;

(19) Division 30: manufacture of other transport equipment;

(20) Division 31: manufacture of furniture; and

(21) Division 32: other manufacturing.

As of 3 April 2017, there were 36,731 manufacturing enterprises registered in the Silesian province. The status of the surveyed manufacturing enterprises was active during the analysis [4,7].

Ten percent of enterprises meeting the time and spatial criteria were selected for the preliminary research. A random number generator was applied to determine which enterprises from the list are included in the sample. A request for participation in the survey was sent to the selected enterprises. A positive reply was received from 310 enterprises. Regarding the size of the sample (research of both the enterprises and employees of the selected enterprises), high costs, and the time-consuming nature of the research, the sample was not broadened. For the survey of employee innovation, 2 employees were selected for each of the micro enterprises, 5 for small enterprises, 10 for medium-sized enterprises, and 20 for large enterprises, with a total sample of 911 employees $[8,9]$.

The surveying process was carried out during meetings in the production enterprises' premises, through telephone and electronic interviews (receiving the filled-in survey questionnaire by electronic means). One of the employed motivating elements intended to obtain a greater number of responses was the organization of free OHS trainings and other courses available to choose from for employee teams in the surveyed production enterprises. The research was carried out between 01.10.2016 and 03.10.2017, additionally confirming the validity of data in April 2018 (verification of the economic activity status in the analyzed enterprises), complementing and obtaining additional data from the interviews conducted with employees of the production enterprises.

Statistical analysis methods were used to develop the research results: descriptive statistics measures and statistical tests: random sample test, chi-square independence test, and non-parametric Kruskal-Wallis test. The random sample test, also called the series test, verifies the zero hypothesis:

$\mathbf{H}_{\mathbf{0}}$ : The sample is random.

towards the alternative hypothesis:

$\mathbf{H}_{1}$ : The sample is not random.

The hypothesis verification procedure is as follows:

(1) the determination of $\mathrm{Me}$ median from the sample;

(2) assign each element of the sample with $x_{i}$, according to the order of sampling the test items, the symbol $a$, if $\mathrm{x}_{i}<M e$, or the symbol $b$, if $\mathrm{x}_{i}>M e$, the result $\mathrm{x}_{i}=M e$ can be ignored;

(3) determination of the total number of $k$ series, where a series is any sub-string of a series of $a$ and $b$ elements, having the property that all consecutive elements of the sub-string are of the same type,

(4) assuming that the zero hypothesis is true, the number of $k$ series has a known and tabulated distribution;

(5) the rejection area is two-sided. From the distribution tables for the series numbers for the presumed significance $\alpha, n_{1}$ and $n_{2}$ (abundance $a$ and $b$ ) we take such critical values $k_{1}$ and $k_{2}$, so relationships $P\left(k \leq k_{1}\right)=\frac{\alpha}{2}$ and $P\left(k \leq k_{2}\right)=1-\frac{\alpha}{2}$ can occur,

(6) provided $k \leq k_{1}$ or $k \geq k_{2}$ the hypothesis of randomness of the sample is rejected, whereas when $k_{1}<k<k_{2}$ there's no basis for rejecting the hypothesis of randomness of the sample. 
Where the sample is large, i.e., $n_{1}>20$ or $n_{2}>20$; the above tables cannot be used because with the increase in the number of $n_{1}$ and $n_{2}$, the distribution of the number of series $k$ tends to a normal distribution, so that the value of the $\mathrm{Z}$ statistic has the following form:

$$
Z=\frac{k-\left(\frac{2 n_{1} n_{2}}{n_{1}+n_{2}}+1\right)}{\sqrt{\frac{2 n_{1} n_{2}\left(2 n_{1} n_{2}-n_{1}-n_{2}\right)}{\left(n_{1}+n_{2}\right)^{2}\left(n_{1}+n_{2}-1\right)}}}
$$

From the normal distribution tables $N(0,1)$, a critical value is determined as $u_{\alpha}$ to have the following relationship for a predetermined materiality level $\alpha: P\left(|Z| \geq u_{\alpha}\right)$. If the value of the sample $U$ statistics is such that $|Z| \geq u_{\alpha}$, we reject the $H_{0}$ hypothesis, whereas when $|Z|<u_{\alpha}$, there are no grounds to reject the $H_{0}$ hypothesis.

The chi-square independence test verifies the hypothesis:

$\mathbf{H}_{\mathbf{i}}:$ Two variables are independent.

towards the alternative hypothesis:

$\mathbf{H}_{\mathbf{j}}$ : Variables are dependent.

A verifying statistics is:

$$
\chi^{2}=\sum_{i=1}^{l} \sum_{j=1}^{k} \frac{\left(n_{i j}-\hat{n}_{i j}\right)^{2}}{\hat{n}_{i j}}
$$

where:

- $\quad n_{i j}$ : actual values

- $\quad \hat{n}_{i j}$ : theoretical values calculated according to the formula $\hat{n}_{i j}=\frac{n_{i} n_{j}}{n}$

The test statistic, assuming that the zero hypothesis is true, has the following distribution $\chi^{2}$ with $(k-1)(l-1)$ degrees of freedom, where $k$ indicates the number of columns (number of variants of the first attribute) of the analyzed cross table and $l$ indicates the number of rows (number of variants of the second attribute). The critical area of this test is the right-hand area $\left[\chi_{\alpha}^{2} ; \infty\right]$ where $\chi_{\alpha}^{2}$ is the critical value read from the distribution tables $\chi^{2}$ for the predetermined significance level $\alpha$.

The Kruskal-Wallis test is used to compare average values between groups. It is a non-parametric alternative for the single-factor variance analysis, ANOVA. ANOVA single-factor variance analysis can be used in the case of random samples, compliant with a normal distribution with groups similar in terms of numbers. The Kruskal-Wallis test does not demand meeting the requirements for the ANOVA variance analysis. These requirements are often difficult to meet, especially in a situation where lack of funds does not allow to broaden the sample, or when the surveyed population is small. The only requirements for the Kruskal-Wallis test are [13,19]:

(1) The dependent variable should be measured on at least an ordinal scale (it can also be measured on a quantitative scale) and

(2) the observations in the analyzed groups should be independent of each other, which means that a person remaining in one group should also be available in another comparable group.

The research results are presented in the paper in a graphic and table format.

\section{Results}

The survey covered owners and managers of 310 production enterprises operating in the Silesian province. These enterprises were randomly selected from a population of all production enterprises, resulting in a sample of varied enterprises, in terms of both the profile of activity and its age. The obtained sample was random and was confirmed by the results of the series test 
$Z=-1,538 ; p=0,124$. There were no grounds to reject the hypothesis of a random character of the sample.

The surveyed production enterprises had existed on the market for 20.8 years on average. The youngest company was 1 year old, and the oldest one was 141 years old. The standard deviation of the surveyed enterprises' age was 18.16 years, meaning that the coefficient of variation was at the level of $87 \%$. This means the surveyed enterprises have large diversity. A typical company had existed on the market for 2.6-39.9 years, thus typical enterprises were almost $94 \%$ of the sample. Only three enterprises were younger than those typical. There were 16 older enterprises, and they accounted for almost $5 \%$ of the surveyed group. The surveyed group was characterized by a right asymmetry, meaning that there were more young enterprises (Figure 1).

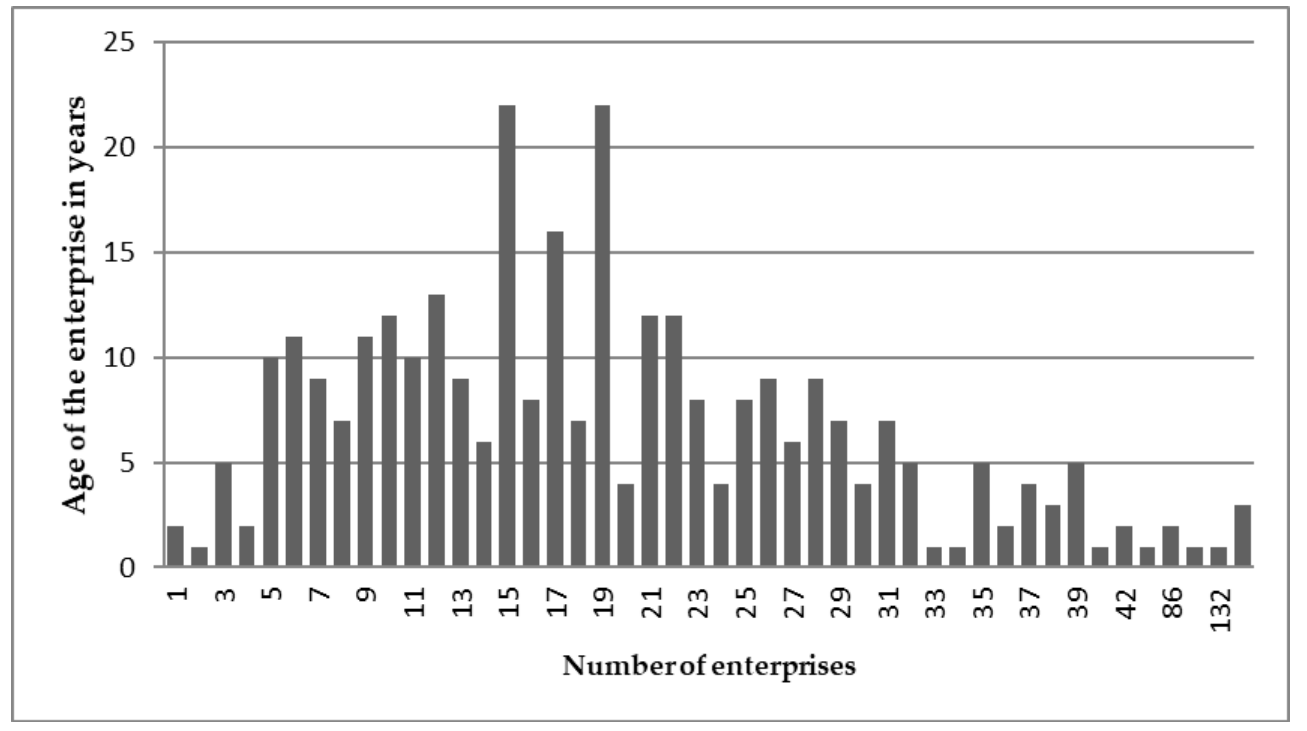

Figure 1. The age of the surveyed production enterprises. Source: own study based on data from questionnaires.

The vast majority of surveyed enterprises, i.e., as much as $72.58 \%$, were micro enterprises employing up to nine employees. Every fifth enterprise (21.94\%) was a small enterprise with 10 to 49 employees. Less than $5 \%$ of enterprises were medium enterprises employing from 50 to 249 employees. Large companies account for only $0.65 \%$ of the surveyed manufacturing enterprises (Figure 2).

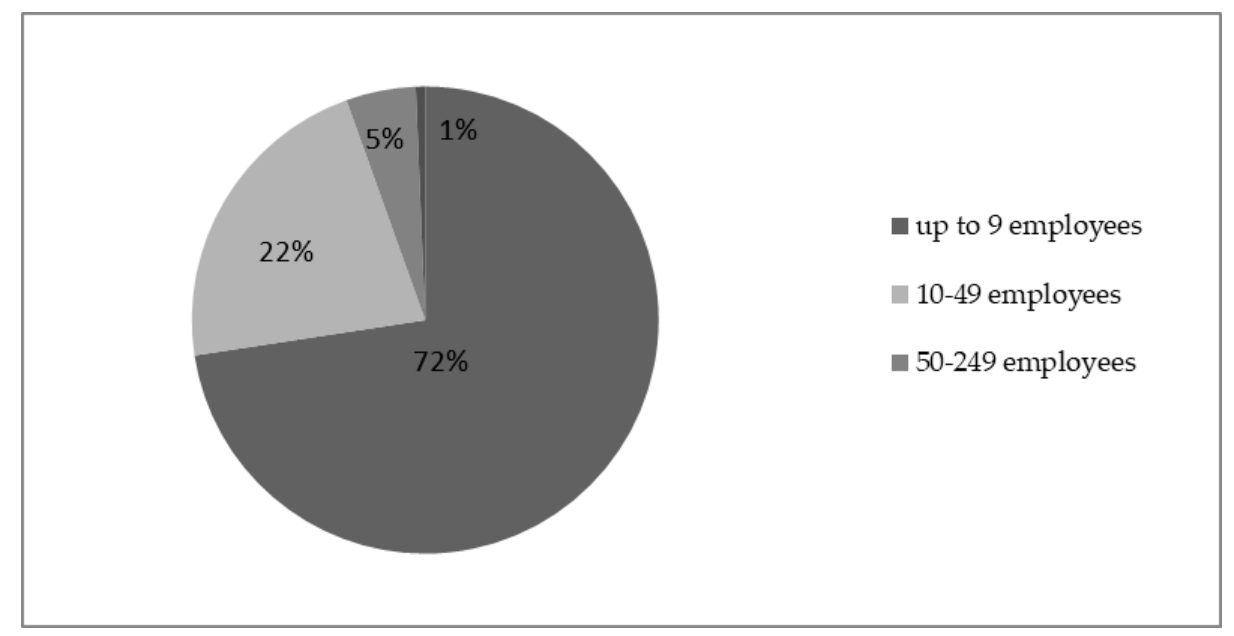

Figure 2. Structure of the surveyed production enterprises by employment size. Source: own study based on data from questionnaires. 
Having the data on the enterprises age and employment size, the hypothesis that the average age of companies depends on the enterprise size has been verified. Results of the Kruskal-Wallis test $H(3)=3,757 ; p=0,289$ carried out did not allow to confirm this hypothesis. No differences were found between the average ages of particular groups of enterprises by size of employment. The average age of micro, small and large enterprises was 17 years (Figure 3). The average age of the medium-sized enterprises was 20 years. The difference was not statistically significant.

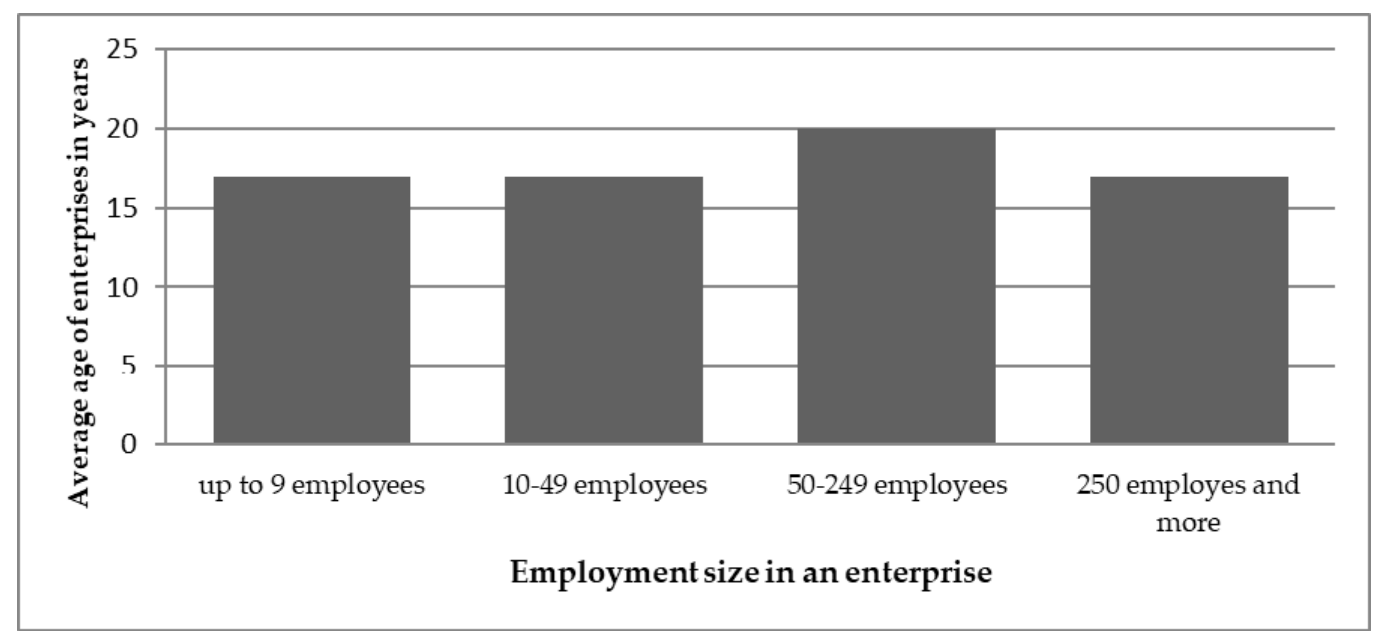

Figure 3. Average age of enterprises by employment size. Source: own study based on data from questionnaires.

The majority of surveyed enterprises $(69 \%)$ covered the area of the whole country with their scope of activity. Every fifth enterprise $(20 \%)$ operated on the international market. The smallest group was constituted by enterprises of local range (11\%) (Figure 4).

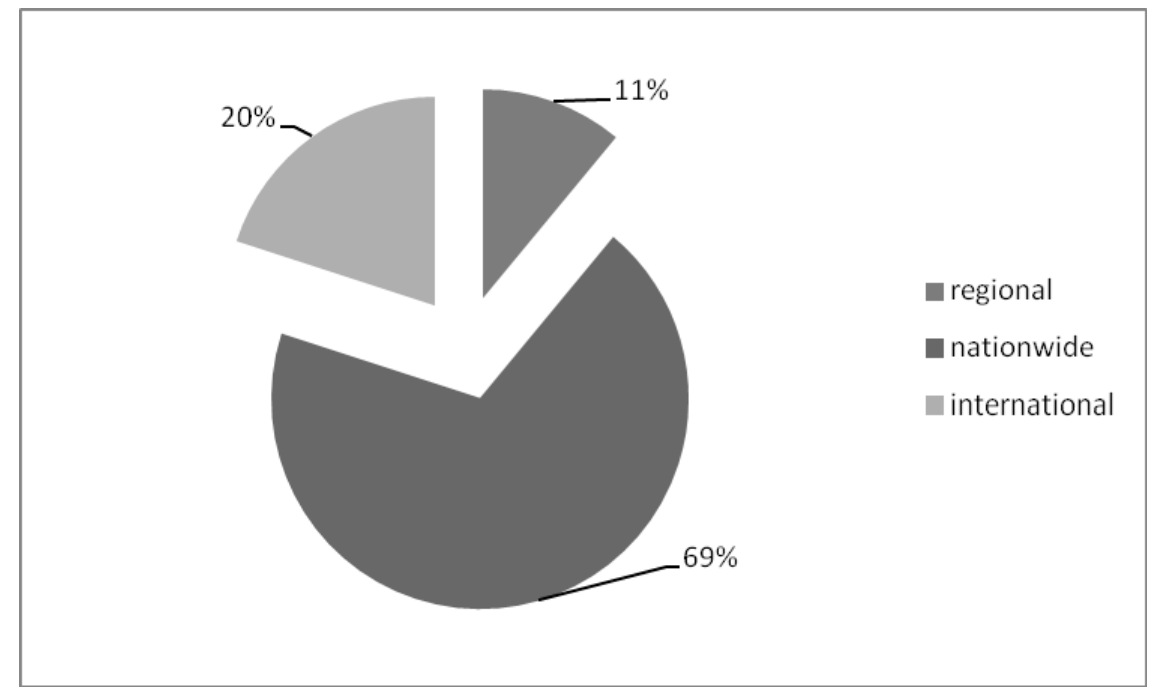

Figure 4. Structure of the surveyed enterprises by scope of activity. Source: own study based on data from questionnaires.

The enterprise age may determine the range of enterprise operations. Longer-established companies may have greater range of operation. Results of the Kruskal-Wallis test $H(2)=0,934 ; p=0,627$ carried out did not allow to confirm this assumption. There were no statistically significant differences in the length of existence of enterprises by the range of their operations. The average age of the enterprises operating on a regional and international market was 16 years, and the enterprises operating on the national market, 17 years. 
The range of operations of the companies can also depend on the size of the enterprise. Larger companies may need a larger range of activities. Results of the conducted chi-square independence test $\chi^{2}(6)=2,012 ; p=0,919$ did not confirm this presumption in relation to the surveyed companies. The majority of micro, small and medium-sized enterprises were of nationwide range. All analyzed large enterprises covered the territory of the whole country with their range. Differences in enterprise structure by employment size and range of operations were not statistically significant (Figure 5).

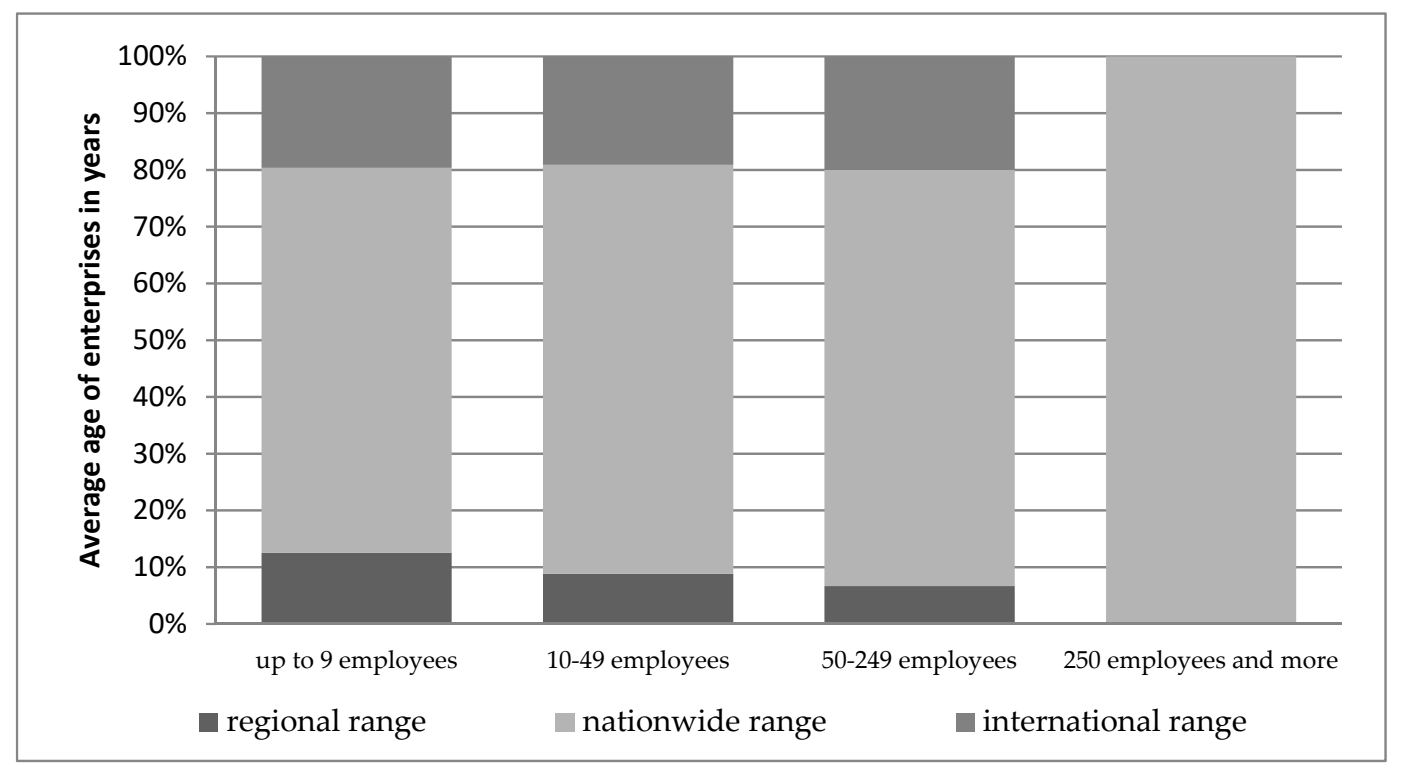

Figure 5. Structure of enterprises by employment size and range of activity. Source: own study based on data from questionnaires.

The success of an enterprise may depend on its competitive advantage resulting from the introduced innovations. Innovations may be of various characters. The majority of surveyed enterprises $(58 \%)$ introduced such innovations in which the respondents were unable to determine the character of or could not decide whether the innovations had been implemented at all. Fifteen percent of companies introduced product innovations. Every 10th surveyed company introduced organizational innovations $(10 \%)$ or process innovations $(10 \%)$. Marketing innovations were introduced by $7 \%$ of the surveyed production enterprises. In total, about $42 \%$ of the surveyed enterprises introduced some specific innovations (Figure 6).

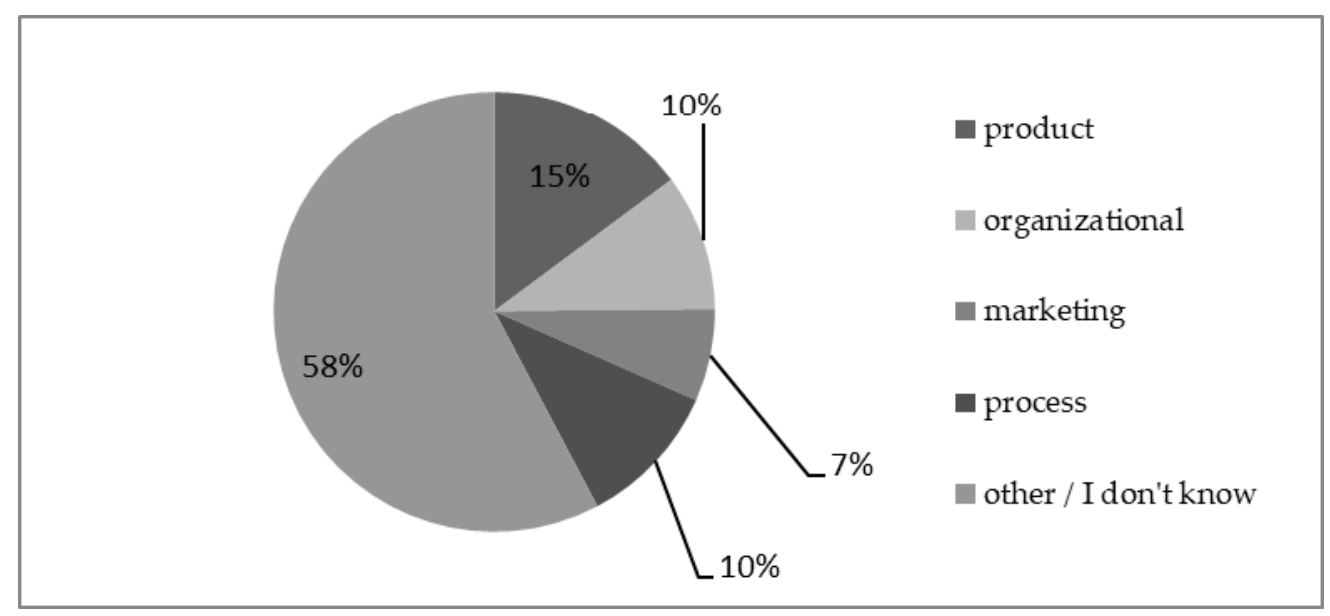

Figure 6. Structure of surveyed enterprises by the range of activity. Source: own study based on data from questionnaires. 
The type of introduced innovations may depend on how long the company has been operating on the market. Results of the Kruskal-Wallis test $H(4)=2,380 ; p=0,666$ did not confirm this hypothesis. There were no statistically significant differences between the average length of existence of the surveyed enterprises by the type of innovations introduced. The enterprises that introduced the product innovations had existed on the market for 18 years on average, similarly to the enterprises that introduced the marketing innovation. The enterprises which introduced the organizational innovations had existed on the market for 16 years on average. The longest-established companies on the market were those that introduced process innovations. Companies that did not introduce any innovations or introduced some innovations of other nature had existed on the market for 16 years.

The employment size may determine the type of introduced innovations. Results of the conducted chi-square independence test $\chi^{2}(12)=15,066 ; p=0,238$, however, they do not confirm this presumption for the surveyed production enterprises. The type of introduced innovations did not depend on the size of surveyed enterprises. Micro, small and medium-sized enterprises introduced the process, organizational, product, or marketing innovations to a similar degree (Figure 7).

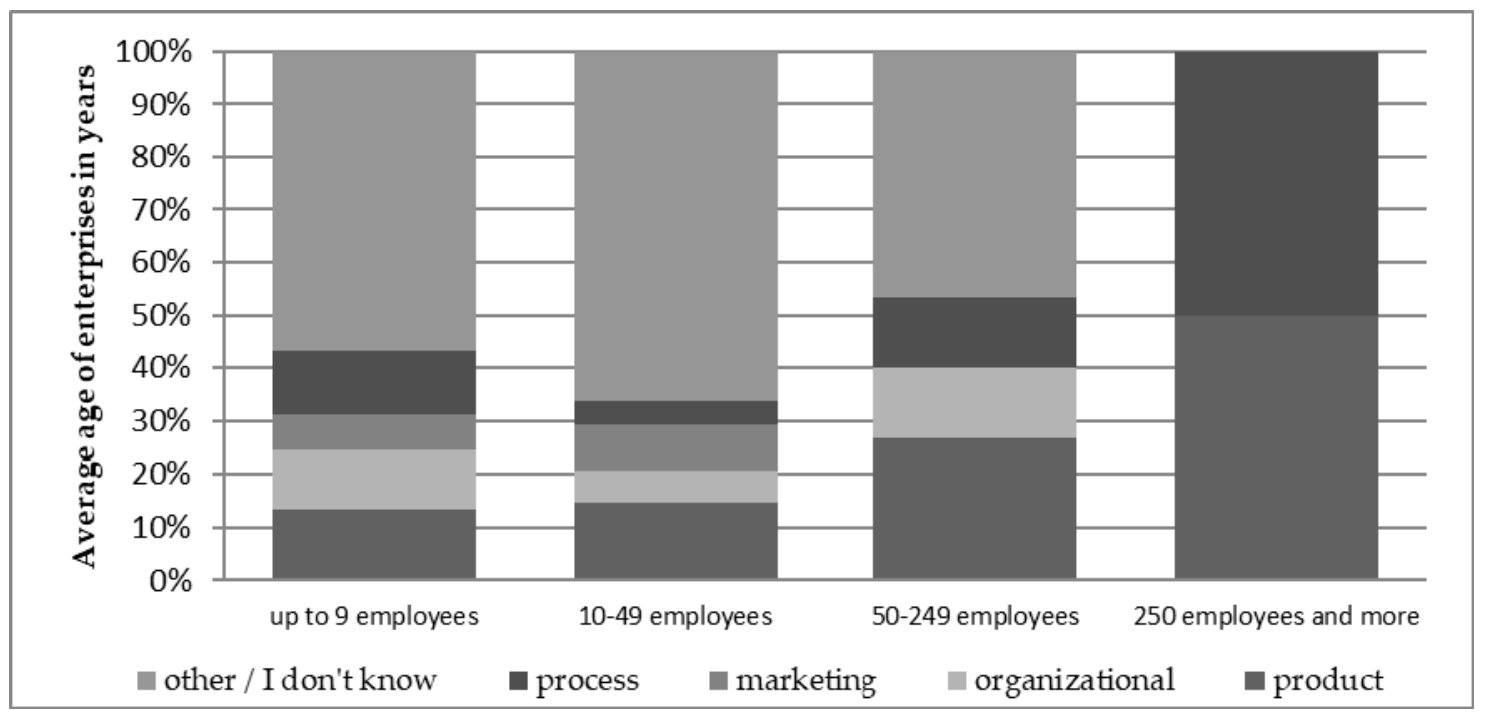

Figure 7. Structure of enterprises by employment size and type of introduced innovations. Source: own study based on data from questionnaires.

The range of enterprise's activity may determine the introduction of innovations. This assumption made in relation to the surveyed production enterprises has not been confirmed. Results of the Chi-square independence test $\chi^{2}(8)=5,979 ; p=0,650$ clearly indicate that there is no link between the type of innovation introduced and the range of activity of the surveyed manufacturing enterprises. However, they do not confirm this presumption for the investigated companies. Regardless of the range of enterprise's activity, the largest number of companies did not introduce any innovations or introduced some innovations of an unspecified nature (Figure 8). 


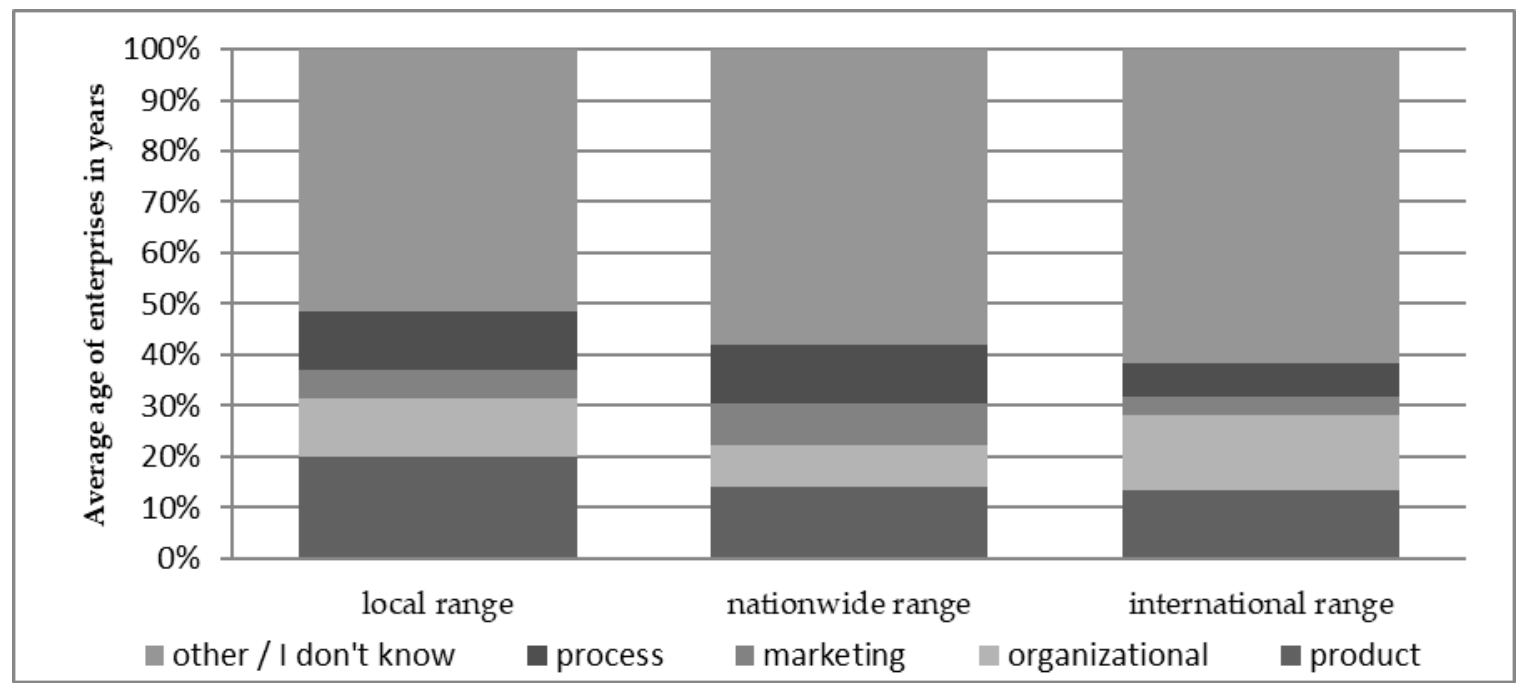

Figure 8. Structure of enterprises by range of activity and type of introduced innovations. Source: own study based on data from questionnaires.

Introduction of innovations may be supported by an innovation unit in some enterprises. Only $9 \%$ of the surveyed enterprises had such an innovation unit (Figure 9).

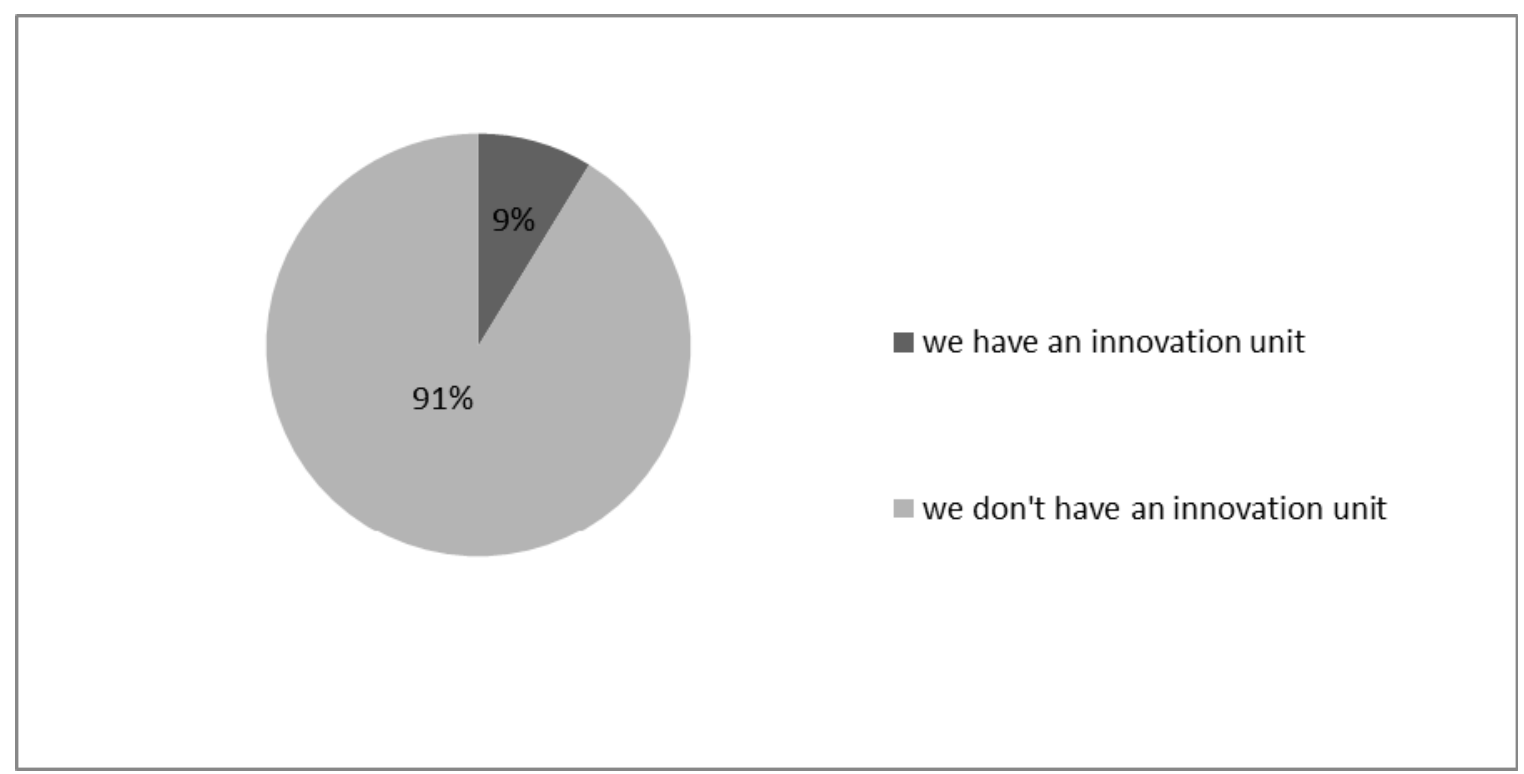

Figure 9. Structure of surveyed enterprises depending on whether they have an innovation unit or not. Source: own study based on data from questionnaires.

Having an innovation unit could depend on the age of the enterprise, its size, and range of activity. The results of the U-Mann-Whitney test $Z=-1,000 ; p=0,317$ did not show any differences between the average company's existence due to the fact that there is an innovation unit. The average age of an enterprise having such a unit and not having such a unit was the same, and amounted to 17 years (Figure 10). 


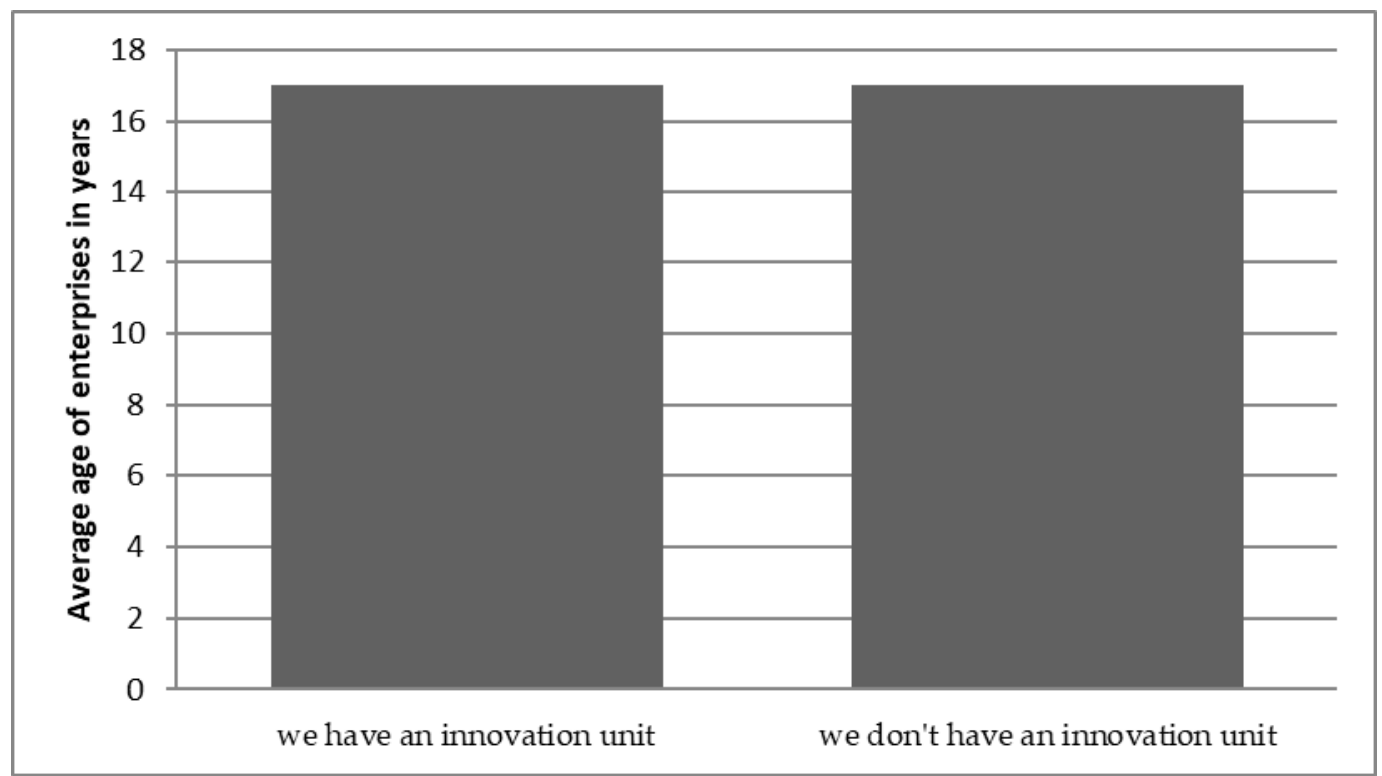

Figure 10. Average age of the enterprises depending on whether they have an innovation unit or not. Source: own study based on data from questionnaires.

The surveyed manufacturing enterprises most often did not have an innovation unit regardless of the size of the company (Figure 11), which was confirmed by the results of the chi-square independence test $\chi^{2}(3)=5,373 ; p=0,146$.

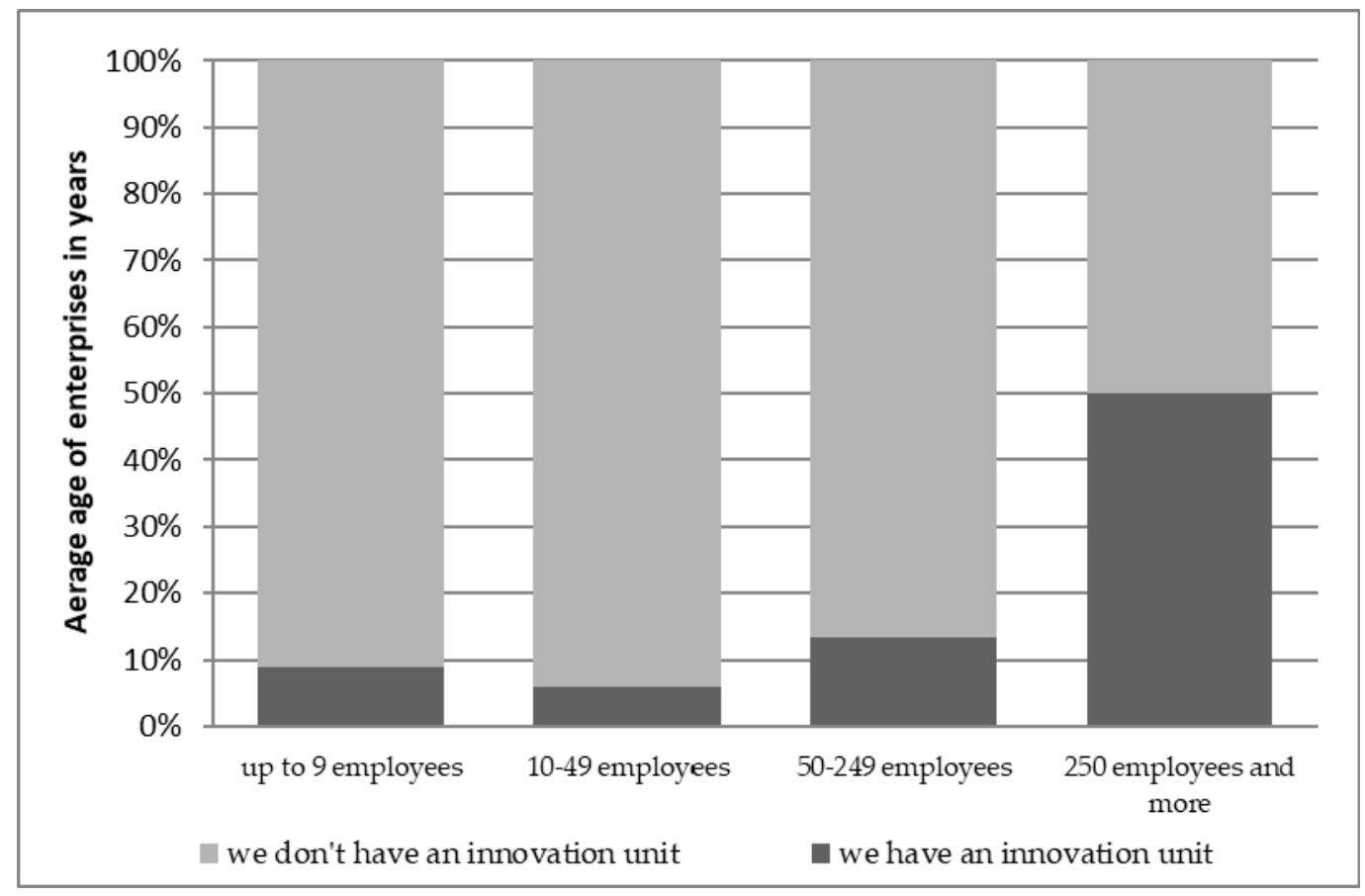

Figure 11. Structure of enterprises by employment size and type of introduced innovations. Source: own study based on data from questionnaires.

In the case of the surveyed enterprise, a statistically significant determinant for having an innovation unit was the range of the enterprise's activity which was confirmed by the chi-square independence test results $\chi^{2}(2)=6,962 ; p=0,031$. In most cases, these were the local-range enterprises that had the innovation unit, and such a unit was present in the international-range companies least often. The greater the range of an enterprise, the less often it had an innovation unit (Figure 12). 


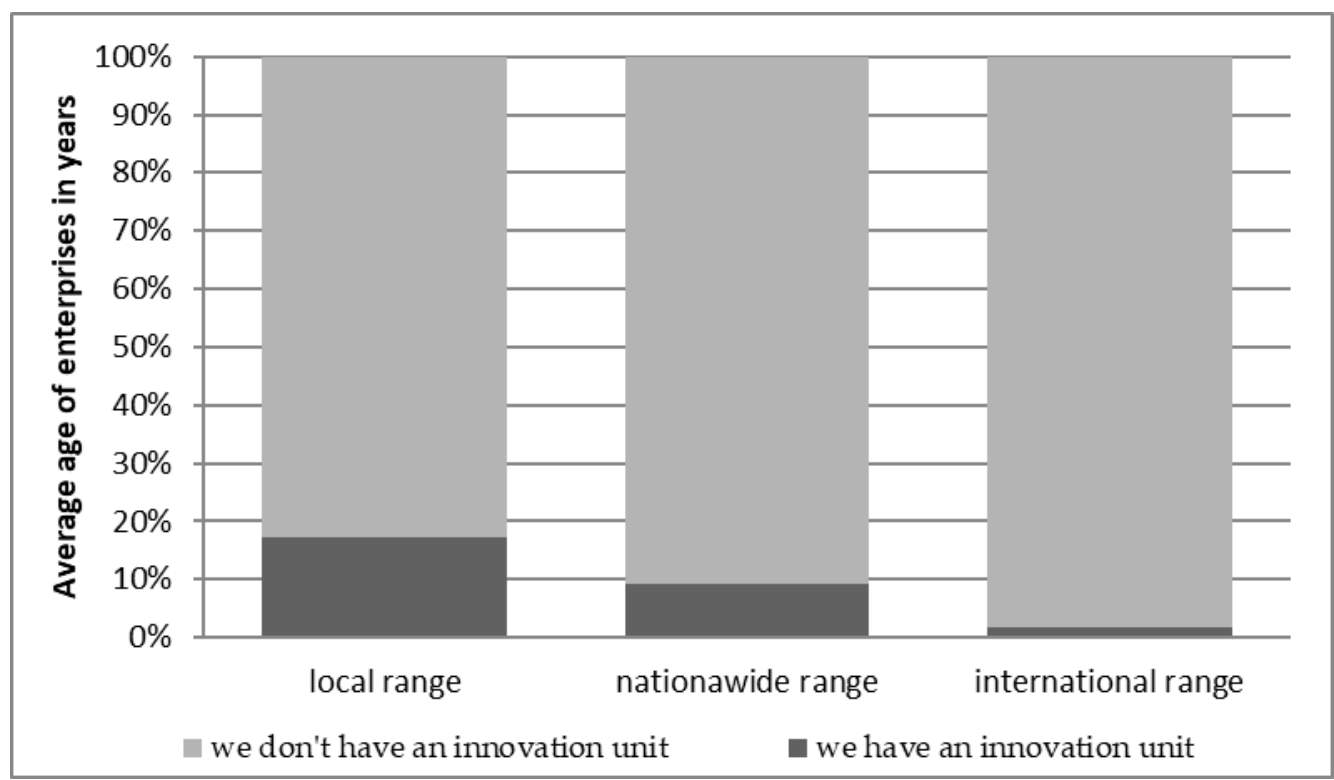

Figure 12. Structure of enterprises by employment size and type of introduced innovations. Source: own study based on data from questionnaires.

In the surveyed enterprises, having an innovation unit did not influence the type of innovations introduced, which was confirmed by the chi-square independence test $\chi^{2}(4)=1,017 ; p=0,907$. Therefore, having an innovation unit did not improve the frequency of innovations introduction among the surveyed enterprises (Figure 13). The innovations were introduced regardless of works carried out in the specialized units of the surveyed enterprises.

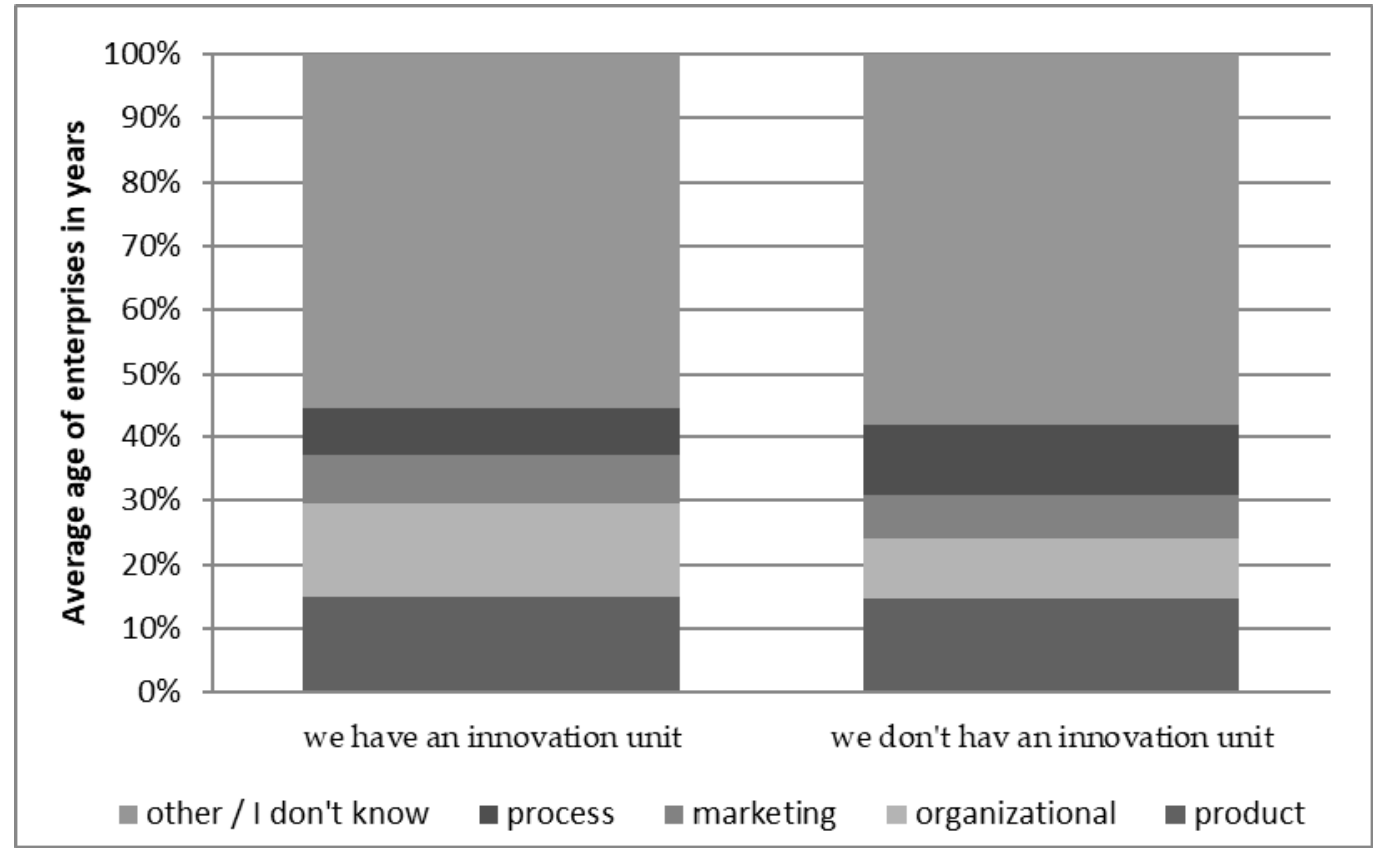

Figure 13. Structure of enterprises depending on whether they have an innovation unit or not and the type of introduced innovations. Source: own study based on data from questionnaires.

In conclusion, it should be noted that the surveyed enterprises were diverse in terms of age, range of activities and size of employment. These features did not have a significant statistical impact on the type of innovations introduced. The innovations were also not dependent on whether an enterprises had an innovation unit or not. The age of the enterprise and its size also did not impact 
the fact of having an innovation unit or not. However, this was statistically significantly influenced by the range of the enterprise's operation. The lower the range, the more often an enterprise had an innovation unit. It should therefore be recognized that the determinant of introducing innovations should be sought outside factors such as the age of the enterprise, the range of the enterprise's activity, the size of the enterprise, and the fact of having an innovation unit or not. Therefore, the factors that decide the innovations may include: barriers for introduction of innovations in the enterprise, contacts with other enterprises, R\&D centers and counseling institutions, and competitive position of the company.

In the vast majority, the surveyed manufacturing enterprises (65\%) faced a lack of capital for growth, which may be reflected in issues with introducing innovations. One in five enterprises reported a lack of skilled workers as a barrier to growth, while 15\% reported outdated technology (Figure 14).

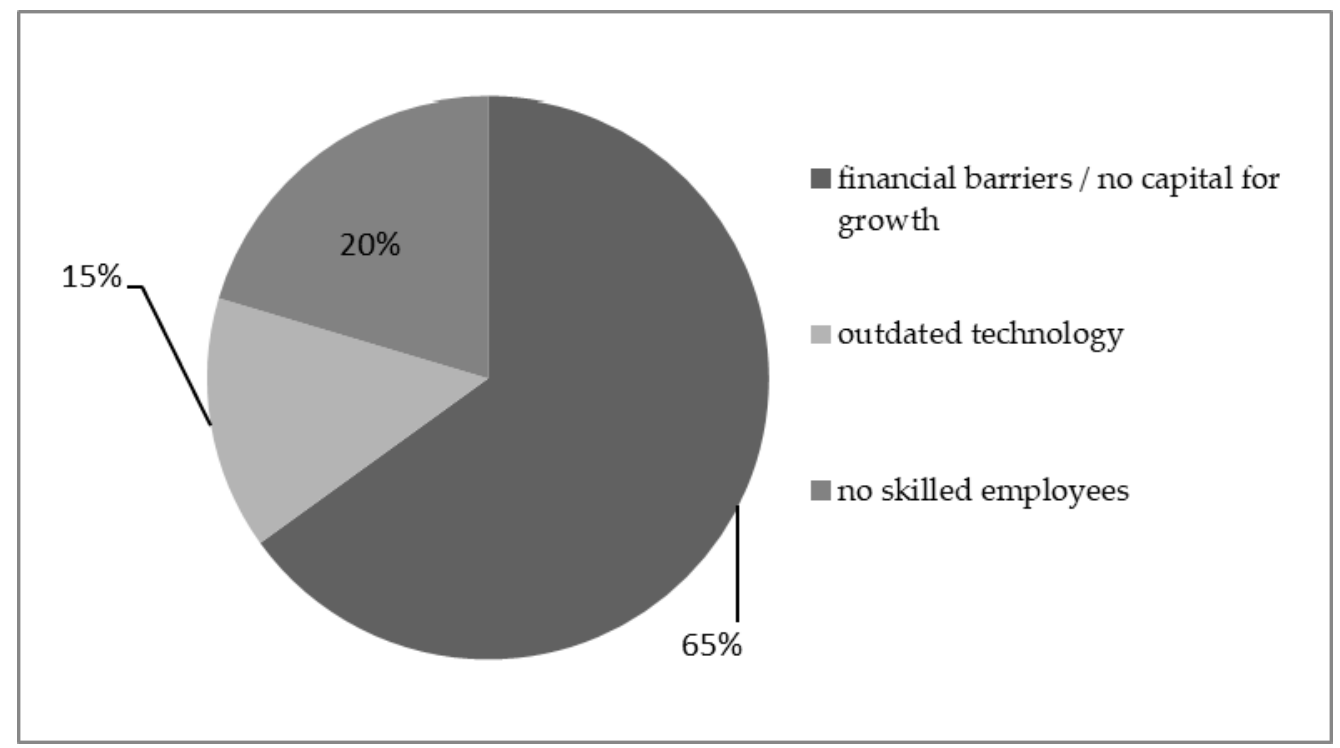

Figure 14. Structure of researched enterprises by barriers to growth. Source: own study based on data from questionnaires.

Barriers faced by the analyzed companies did not depend on the age of the enterprises, which was confirmed by the results of the Kruskal-Wallis test $H(2)=2,648 ; p=0,266$. The enterprises complaining of lack of capital for growth had operated on the market for 17 years on average. The companies that recognized an outdated technology as the barrier to growth had existed for 14 years on average, and the companies complaining about lack of skilled workers, 18 years on average. The differences among the listed average values were not statistically significant (Figure 15). 


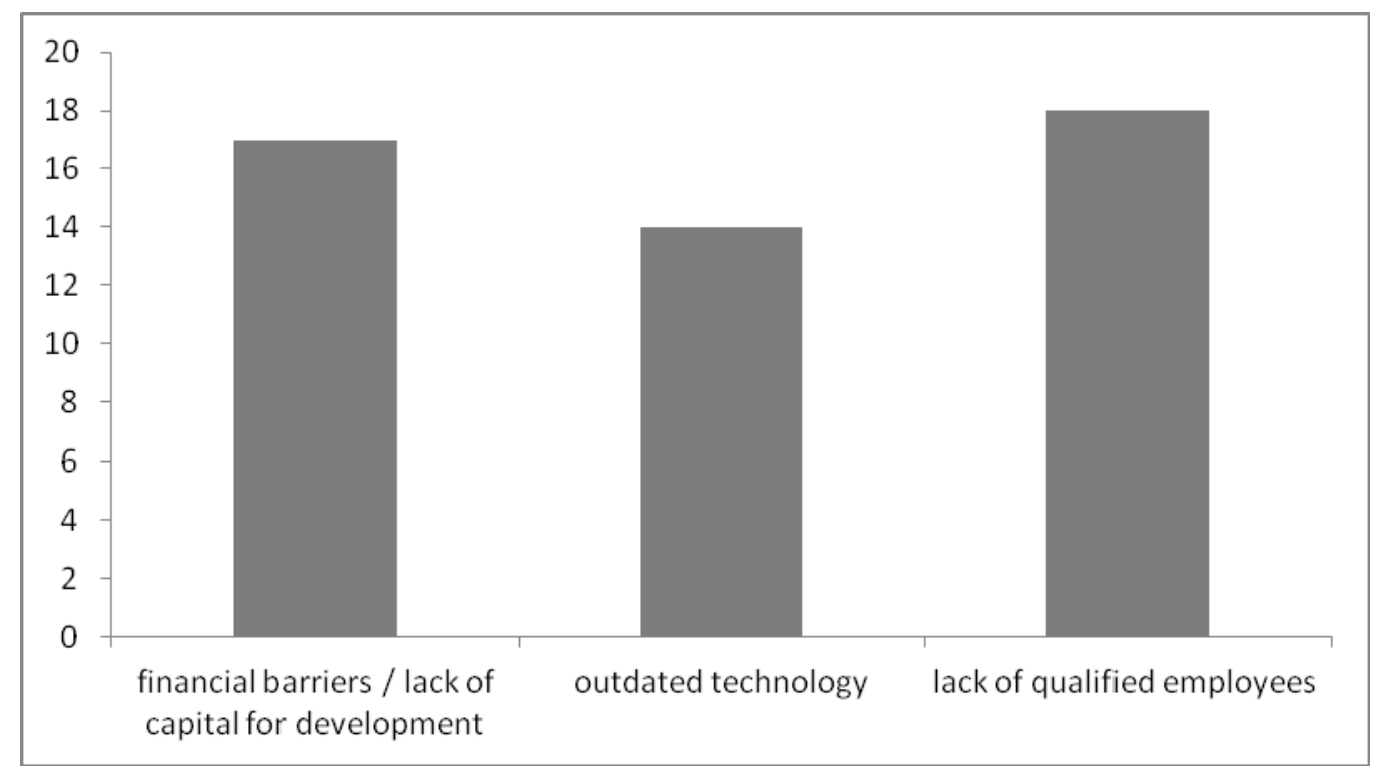

Figure 15. Average age of enterprises by type of introduced innovations. Source: own study based on data from questionnaires.

The development barriers faced by the surveyed companies depended on the size of the surveyed companies (chi-square independence test $\chi^{2}(6)=12,808 ; p=0,04$ ). Large enterprises more often faced the problem of outdated technology, and smaller ones faced the problem of financial barriers. The larger the enterprise, the more often barriers of outdated technology were present, and the smaller the enterprise, the more often there was a lack of qualified personnel (Figure 16).

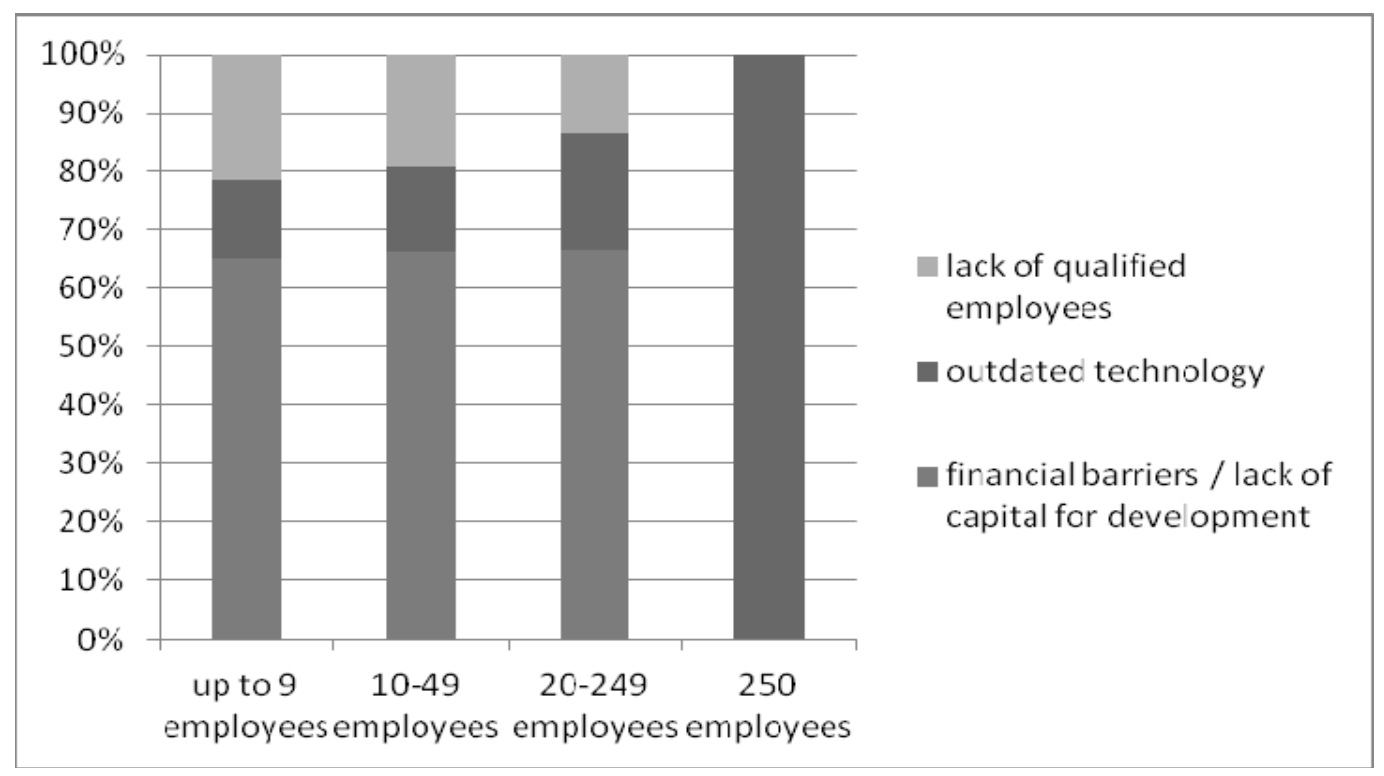

Figure 16. Structure of enterprises by size of employment and development barriers. Source: own study based on data from questionnaires.

The development barriers faced by the surveyed companies depended on the size of the surveyed companies' chi-square independence test $\chi^{2}(12)=15,066 ; p=0,238$. Large enterprises more often faced the problem of outdated technology, and smaller enterprises, the problem of financial barriers. The larger the enterprise, the more often barriers of outdated technology were present, and the smaller the enterprise, the more often there was a lack of qualified personnel (Figure 17). 


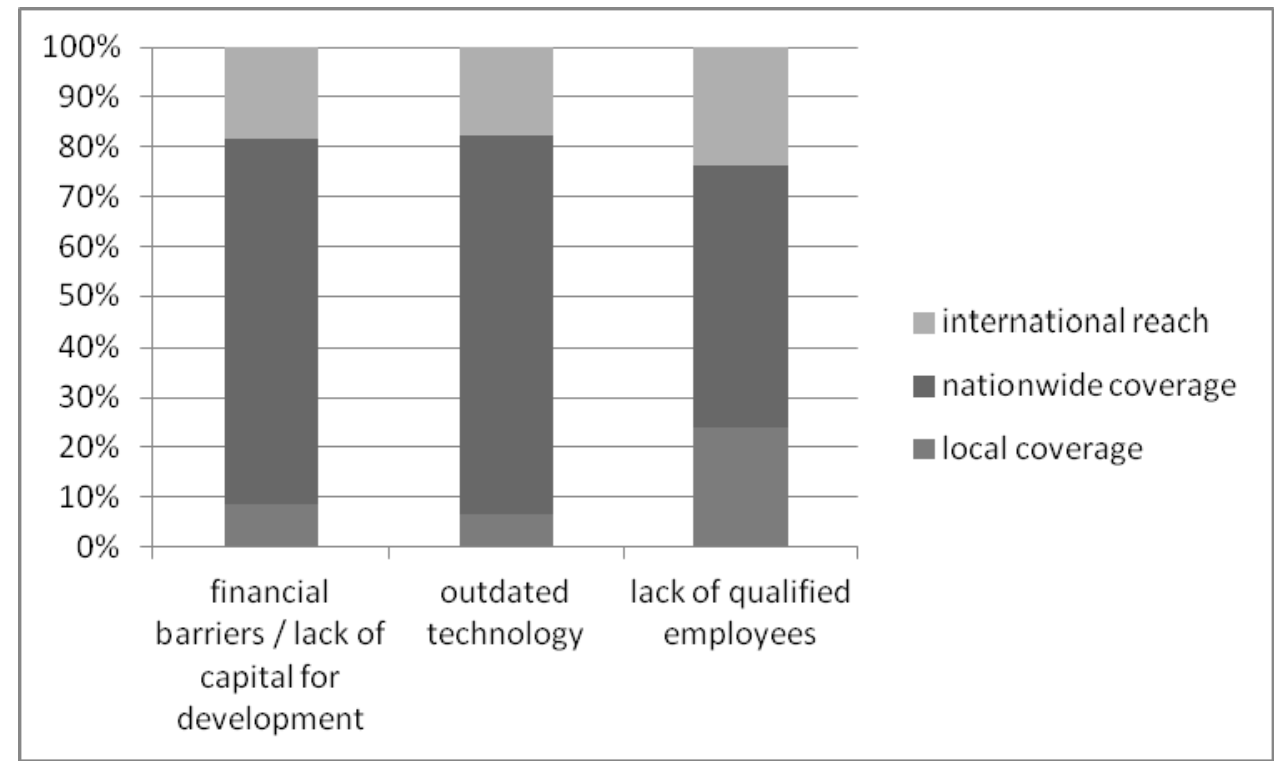

Figure 17. Structure of enterprises according to the scope of activity and barriers to development. Source: own study based on data from questionnaires.

The innovations introduced were independent of the size of the company, the age of the company or the scope of the company, as well as having an innovation unit. While introducing innovations, most often there was no cooperation with other entities, which indicates the own work of the team of employees of the surveyed companies. Nearly 1 in 10 enterprises used consulting companies or business partners to introduce innovations (Figure 18).

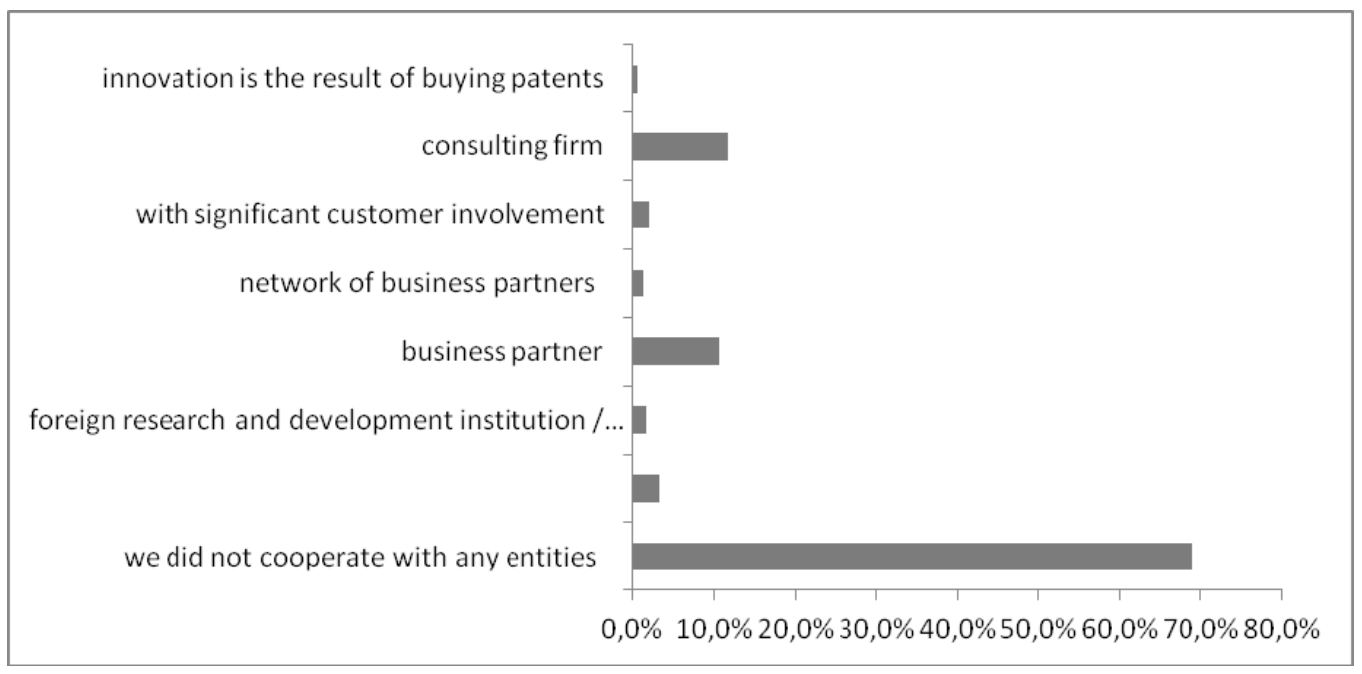

Figure 18. Structure of enterprises by entities cooperating in the implementation innovations. Source: own study based on data from questionnaires.

Investigating the impact of innovation cooperation on the type of innovation introduced showed that a statistically significant relationship occurred in the absence of cooperation with external parties $\left(\chi^{2}(4)=15,395 ; p=0,001\right)$, with significant customer involvement $\left(\chi^{2}(4)=15,751 ; p=0,003\right)$, and with a consultancy firm $\left(\chi^{2}(4)=15,771 ; p=0,003\right)$. The innovation process should therefore be considered to be influenced most by the company's employees and customers.

Employees in the innovation process are a very important link in the company's success. Appropriate incentive systems can increase the effectiveness of the innovation process. In order 
to verify the main hypothesis of this desiderata, the employees of these companies were also examined, in addition to the survey of manufacturing companies.

A sample of 2 employees was selected for micro enterprises, 5 for small enterprises, 10 for medium enterprises, and 20 for large enterprises, resulting in a sample of 911 employees. Among the employees surveyed, the vast majority were men (82\%). Nearly one in five working people in the surveyed companies were woman (18\%). The majority of the surveyed employees $(45 \%)$ had secondary education. Nearly one in three employees had vocational education (32\%). Only $12 \%$ of the surveyed employees had high education. Nearly $3 / 4$ of the employees were privately-held production workers. Regarding position, $12 \%$ of the respondents were managers and $16 \%$ of the respondents were engaged in intellectual work.

The development barriers faced by the surveyed companies depended on the size of thesurveyed companies (chi-square independence test $\chi^{2}(6)=12,808 ; p=0,04$ ). Large enterprises more often faced the problem of outdated technology, and smaller enterprises, the problem of financial barriers. The larger the enterprise, the more often barriers of outdated technology were present, and the smaller the enterprise, the more often there was a lack of qualified personnel (Figure 19).

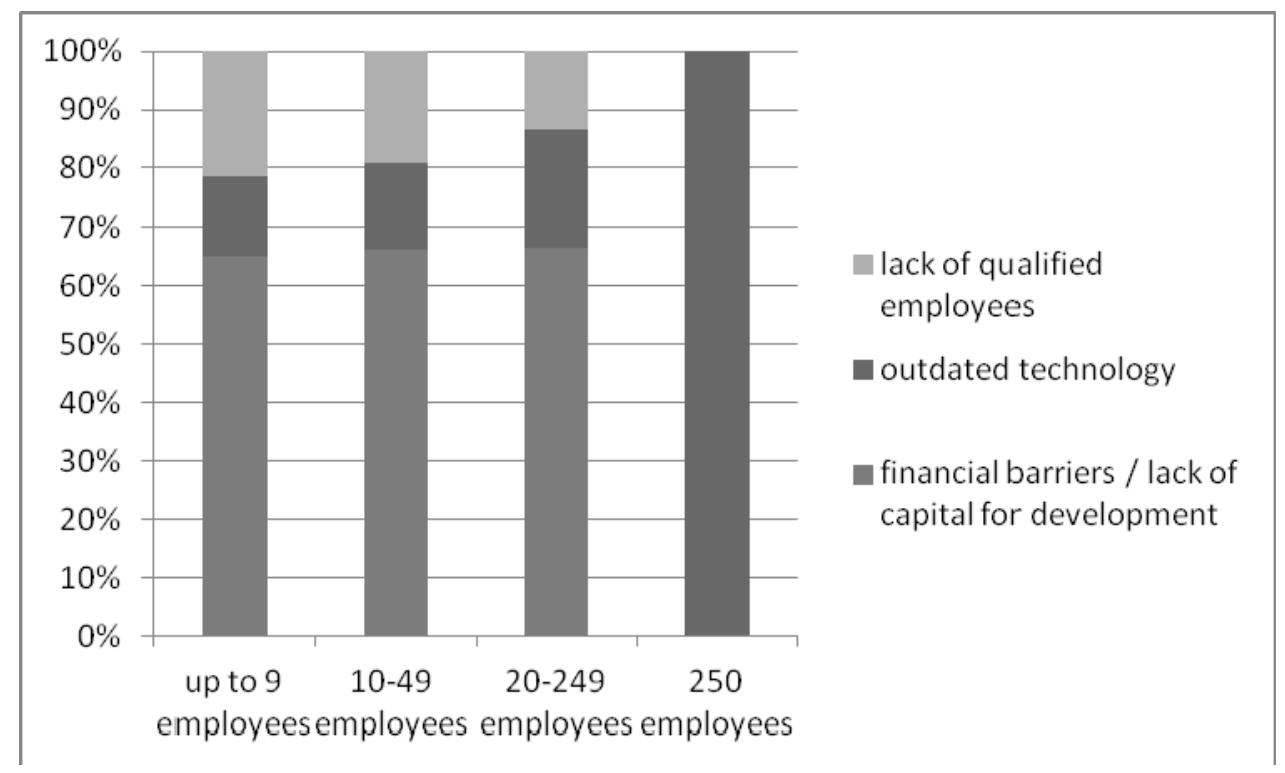

Figure 19. Structure of enterprises by size of employment and development barriers. Source: own study based on data from questionnaires.

A statistically significant determinant of the existence of barriers to the company's development was the scope of the company's activity, which was confirmed by the results of the chi-square chi-square independence test $\chi^{2}(4)=15,069 ; p=0,005$. Companies with local reach were most often indicated by the lack of qualified staff and financial barriers to development. Nationwide companies were most frequently pointed out by financial barriers to development (Figure 20). 


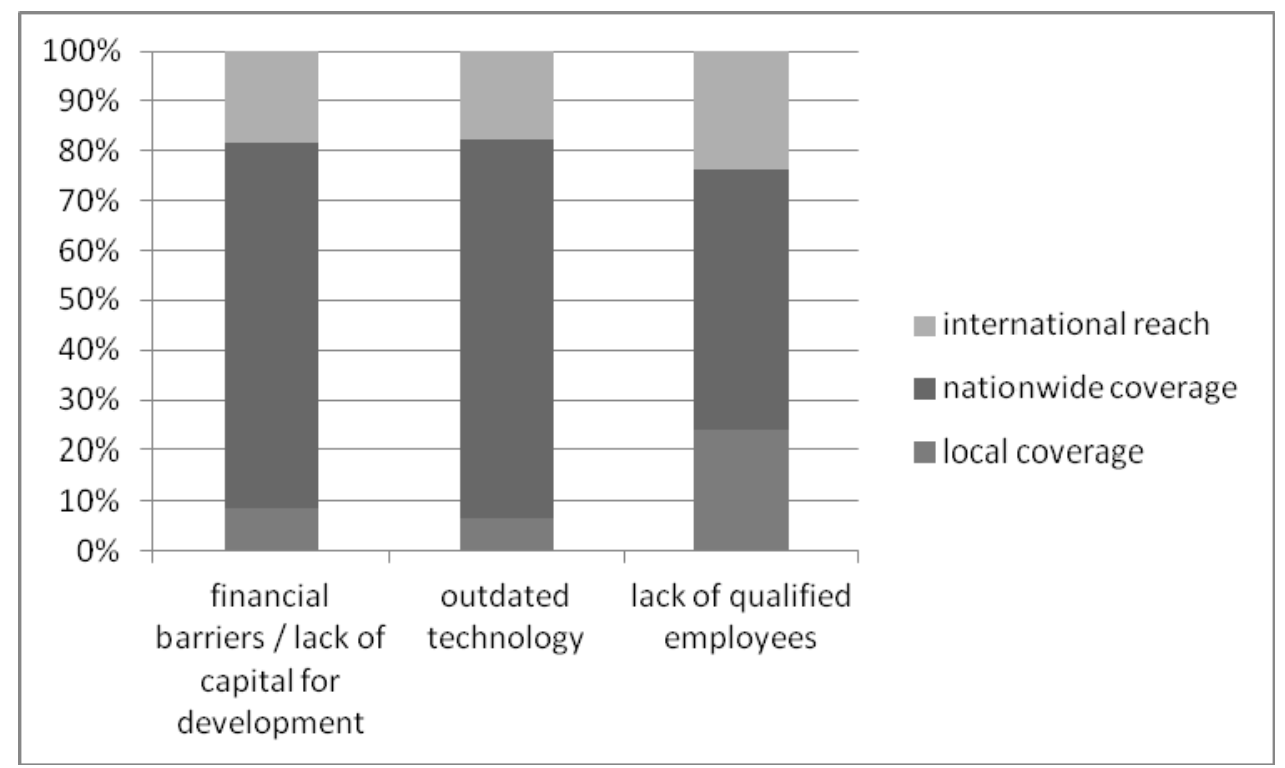

Figure 20. Structure of enterprises according to the scope of activity and barriers to development. Source: own study based on data from questionnaires.

The innovations introduced were independent of the size of the company, the age of the company, or the scope of the company, as well as having an innovation unit. While introducing innovations, most often there was no cooperation with other entities, which indicates the own work of the team of employees of the surveyed companies. Nearly 1 in 10 enterprises used consulting companies or business partners to introduce innovations (Figure 21).

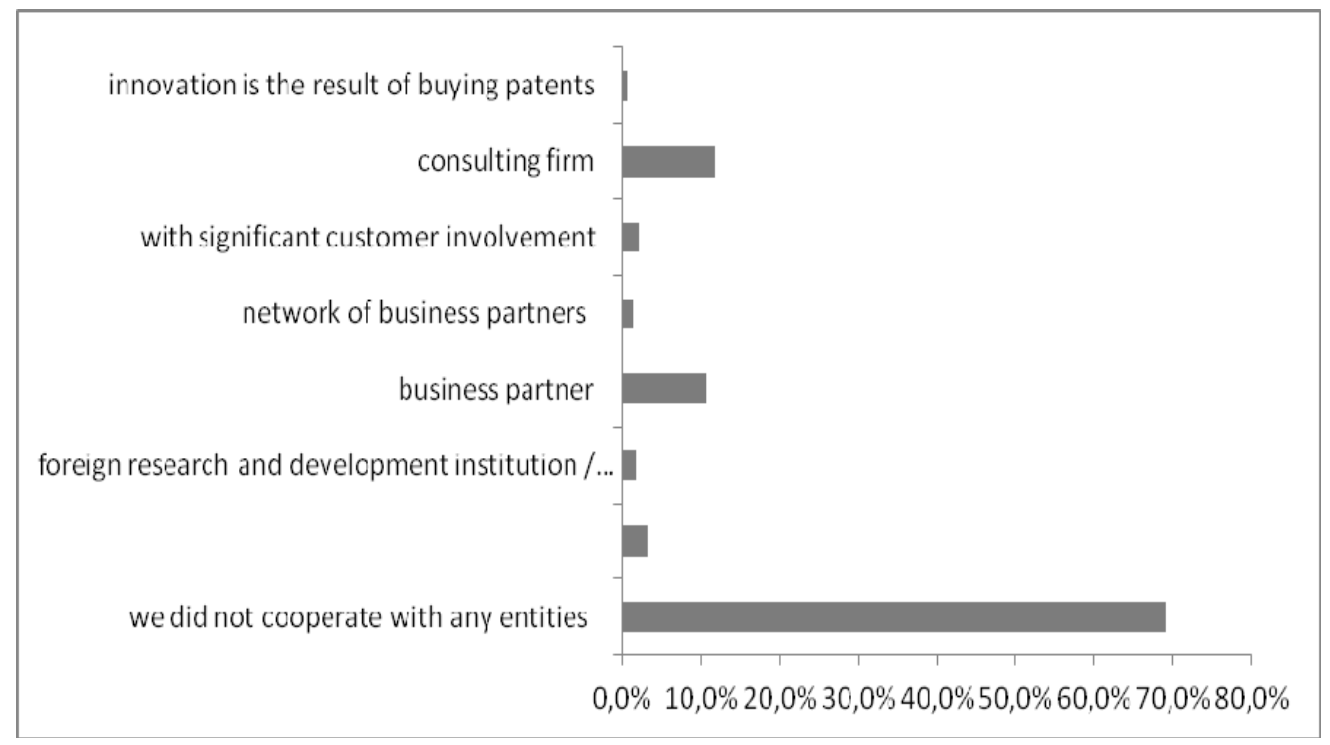

Figure 21. Structure of enterprises by entities cooperating in the implementation innovations. Source: own study based on data from questionnaires.

An examination of the impact of innovation cooperation on the type of innovation introduced showed that a statistically significant relationship occurred in the absence of cooperation with external parties $\left(\chi^{2}(4)=15,395 ; p=0,001\right)$, with significant customer involvement $\left(\chi^{2}(4)=15,751 ; p=0,003\right)$, and in cooperation with a consulting company $\left(\chi^{2}(4)=15,771 ; p=0,003\right)$. The innovation process should therefore be considered to be influenced most by the company's employees and customers. 
Nearly $3 / 4$ of the employees were privately held production workers. Regarding position, $12 \%$ of the respondents were managers and $16 \%$ of the respondents were engaged in intellectual work. The surveyed employees were most often aged from 18 to 34 (about $40 \%$ of the surveyed). Slightly older employees, aged 35-45, made up 34\% of the surveyed. Employees aged 46-59 constituted 22\% of the total number of respondents. Thus, the share of a given age group decreased as the age of the group increased. Length of service is a factor that may be indicative of a good knowledge of the workplace and its attachment to the workplace. A stable employee who is trained in his or her trade can be an invaluable source of success for the company. The majority of the surveyed employees were employees with $2-5$ years of service $(37 \%)$ and less than 2 years of service $(32 \%)$, which at the same time confirms the development barriers identified earlier by the surveyed companies, i.e., the lack of trained staff. A good employee is, among other things, an employee who knows the company, knows how to assess its level of innovativeness, and is motivated to take part in the process of introducing innovations. In $84 \%$ of the surveyed employees of manufacturing companies, the level of innovativeness of their workplace was low. At a high level of $9 \%$ and at an average level of only $7 \%$ of respondents rated the level of innovation in their workplace.

The assessment of the level of innovativeness of the workplace did not depend on the level of education of the employees, which was confirmed by the results of the test chi-square independence test $\chi^{2}(10)=13,152 ; p=0,215$. Despite the differences in the structure of employees according to education and opinion on innovativeness, which is visible in chart 28 , these differences were not statistically significant.

The assessment of the level of innovativeness of the workplace depended on the position taken. Employees holding managerial positions more often evaluated the position of innovativeness as average, white-collar employees more often than others evaluated this position as high, and privately held employees more often than others evaluated this position as low. The assessment of the level of innovativeness of the workplace was not dependent on the employee's gender $\chi^{2}(2)=2,289 ; p=0,318$. Both women and men similarly assessed the level of innovativeness of their workplace.

The assessment of the level of innovativeness of the workplace did not depend on the age, either employee $\chi^{2}(8)=8,654 ; p=0,372$. Employees of all ages were similarly appraised by the level of innovation of their workplace. The assessment of the level of innovativeness of the workplace was also not dependent on the length of service of the employee $\chi^{2}(8)=4,444 ; p=0,815$. Employees similarly assessed the level of innovativeness of their workplace regardless of how much time they worked in it.

The innovation process can be more effective when employees feel and see the need to innovate in their workplace. In the surveyed companies, employees had divided opinions on this subject: $49 \%$ of employees saw a need for innovation, and $51 \%$ did not see a need for innovation. The need to innovate was felt by employees regardless of their level of education. The need to introduce innovation was also felt by employees regardless of the position they held $\chi^{2}(2)=1,312 ; p=0,519$. Employees of the surveyed manufacturing companies regardless of gender similarly commented on the need to innovate in their workplace $\chi^{2}(1)=0,078 ; p=0,880$. The assessment of the need to innovate was felt differently by employees at different ages $\chi^{2}(4)=8,808 ; p=0,044$. Younger workers were less likely to feel the need to innovate. Older workers were more likely to feel the need for innovation in their production facilities.

Assessment of the need to innovate was similarly felt by employees with different seniority $\chi^{2}(4)=2,294 ; p=0,682$. Therefore, seniority did not influence the assessment of the need for innovation.

\section{Discussion and Conclusions}

Authors discuss the results and how they can be interpreted from the perspective of previous studies and of the working hypotheses. The research objective was achieved by performing an analysis of activities influencing innovative actions in manufacturing enterprises of the Silesian province. Small, medium and large enterprises were surveyed. The group of respondents was composed of owners of 
managers of the production enterprises as well as their employees. The subject of the research activities included production enterprises in th Silesian province. The research area covered the Silesian province. The research period was 2011-2016. A total of 310 production enterprises were surveyed in that time. The main limitation of the researched population was the cost and the time-consuming nature of the project. Statistical Offices, Town Halls or Country Office did not have any data on the actual status of active enterprises. The reasons for the lack of this information were: inconsistency in the provision of information by entrepreneurs, for example in relation to cessation of activities; changing reporting formats regarding the enterprise; and intended fraudulent behaviors of the entrepreneurs.

The conducted research suggests that the average age of the enterprises did not depend on their size. The enterprise age may determine the range of enterprises operations. The success of an enterprise may depend on its competitive advantage resulting from the introduced innovations [20]. Innovations may be of various characters. The longest-established companies on the market were those that introduced process innovations.

The type of introduced innovation does not depend on the size of surveyed enterprises, which is confirmed by many other studies [22,28]. Micro, small and medium-sized enterprises introduced the process, organizational, product and marketing innovations to a similar degree. The range of enterprise activities does not determine the introduction of innovations. The introduction of innovations may be supported by an innovation unit in some enterprises. Only $9 \%$ of the surveyed enterprises had an innovation unit. Having an innovation unit could depend on the age of the enterprise, its size and range of activity.

In the case of the surveyed enterprise, a statistically significant determinant for having an innovation unit was the range of the enterprise's activity which was confirmed by the chi-square independence test results $\chi^{2}(2)=6,962 ; p=0,031$. In most cases, these were the local-range enterprises that had an innovation unit, and such a unit was present in the international-range companies least often. The greater the range of an enterprise, the less often it had an innovation unit.

In the surveyed enterprises, having an innovation unit did not influence the type of innovations introduced, which was confirmed by the chi-square independence test $\chi^{2}(4)=1,017 ; p=0,907$. Therefore, having an innovation unit did not improve the frequency of innovations introduced among the surveyed enterprises. The innovations were introduced regardless of works carried out in the specialized units of the surveyed enterprises in relation to age, range of activity and employment size. These features did not have a significant statistical impact on the type of innovations introduced. The innovations were also not dependent on whether an enterprises had an innovation unit or not. The age of the enterprise and its size also did not impact the fact of having an innovation unit or not. However, this was statistically significantly influenced by the range of the enterprise's operation. The lower the range, the more often an enterprise had an innovation unit. It should therefore be recognized that the determinant of introducing innovations should be sought outside factors such as the age of the enterprise, the range of the enterprise's activity, the size of the enterprise, and the fact of having an innovation unit or not. Therefore, the factors that decide about the innovations may include: barriers for introduction of innovations in the enterprise, contacts with other enterprises, R\&D centers and counseling institutions, and competitive position of the company. In the vast majority, the surveyed manufacturing enterprises $(65 \%)$ faced a lack of capital for growth [26,29], which may be reflected in issues with introducing innovations. One in five enterprises reported a lack of skilled workers as a barrier to growth, which is also confirmed by other studies [30]. In addition, an important factor reported in the study was (15\%) outdated technology. The barriers that the analyzed enterprises had to face did not depend on the age of the companies.

Research has shown that the introduction of innovation has a significant impact on improving the efficiency of the economy. The results indicated that the length of the company or its size is irrelevant, but that there are still no activities extended to international markets on the basis of Polish manufacturing companies, but are only local, and most companies do not have specialized dedicated cells to innovate. Another interesting conclusion is that the surveyed production companies 
are primarily focused only on production innovation and minimization of costs, so they do not create cells responsible for creating innovation at all. The demonstration of factors that influence the introduction of many innovations successfully is of fundamental importance for the effective functioning of manufacturing companies competing on the market.

Poland's innovativeness is mainly perceived through the lens of large enterprises, due to the greater financial resources that can be allocated to research and development, as well as the higher qualifications of staff. This way of perceiving innovation meant that innovative activities of manufacturing companies are not significant. According to reports and studies carried out, among others, by the Polish Agency for Enterprise Development, European Innovation Scoreboard, Innovation Union Scoreboard, The Global Competitiveness Report, The European Commission, it results in the fact that production companies in recent years more often undertake activities related to innovation processes [31]. The increase in both government and private sector expenditure over the years and Poland's better international positioning in terms of entrepreneurship conditions indicate that the issue of innovation in the Polish economy is of a developmental nature. Further changes in the ease of doing business, as well as limiting the complexity of Polish law, combined with a high level of education, may result in Poland's promotion as an innovator. All research in production companies towards introducing changes in the field of innovation can significantly affect the economic growth of our country, and thus, improve the structure of innovation.

The innovation survey was conducted because in the context of increasing globalization and increasing competition, the increase in innovation is a strategic challenge for the Polish economy. Innovation, understood as the company's ability to increase motivation in the way it is created and implemented, often depends on the possibility of achieving competitive advantage and effective operation. That is why it is so important to know the determinants affecting the effectiveness of introducing innovations, which was undertaken in this study. The complexity and risk of implementing innovations means that there is a widespread belief in the need to support such processes in various ways [32]. Ensuring efficiency and speed to improve innovation is particularly important. Because the innovation of the Polish economy compared to most EU countries is still at a fairly low level. The Sumary Innovation Index (SII), being the evaluation criterion, is about 300 points, while the EU average is around 450 points [33]. Leading in innovation, such countries as: Sweden, Denmark, Finland, and Germany, achieve more than twice as high innovation rates compared to Poland. At local and regional levels, regional innovation strategies (RSIs), in particular the reality of their implementation, are important instruments for increasing innovation. For the Silesian voivodship, the Regional Innovation Strategy of the Silesian voivodship for the years 2013-2020 has been developed, this being the second document of this type in the region. The first innovation strategy was implemented in the years 2003-2012. The importance of this type of strategic development is associated with the effectiveness of achieving goals and the possibility of implementing broadly understood strategic initiatives. The latest research indicates that Poland is one of the so-called moderate innovators, which results from the European Innovation Ranking published by the Commission in June 2018. Every year, the Commission publishes a comparative assessment of the Member States' results in the field of innovation and compares it with the results of international competitors. The European Innovation Ranking shows that there is a wealth of talent and a desire to increase entrepreneurship in Europe.

Author Contributions: Conceptualization, H.W.; methodology, H.W. and I.M.; software, H.W. and I.M.; validation, H.W. and I.M.; formal analysis, H.W. and I.M.; investigation, H.W. and I.M.; resources, H.W. and I.M.; data curation, H.W. and I.M.; writing—original draft preparation, H.W. and I.M.; writing—review and editing, H.W. and I.M.; visualization, H.W. and I.M.; supervision, H.W. and I.M.; project administration, I.M.; funding acquisition, I.M.

Funding: The project is financed within the framework of the program of the Minister of Science and Higher Education in Poland under the name "Regional Excellence Initiative" in the years 2019-2022, project number 001/RID/2018/19, the amount of financing PLN 10,684,000.00.

Acknowledgments: Many thanks to Joanna Nowakowska-Grunt and Leon Dorozik for scientific support and Justyna Miciuła for administrative and spiritual support. 
Conflicts of Interest: The authors declare no conflict of interest.

\section{References}

1. Ja-Shen, C.; Hung, T.T.; Russell, Ch. Co-production and its effects on service innovation. Ind. Mark. Manag. 2011, 40, 1331-1346.

2. Behrouzi, F.; Wong, K.Y. Lean performance evaluation of manufacturing systems: A dynamic and innovative approach. Procedia Comput. Sci. 2011, 3, 388-395. [CrossRef]

3. Ponds, R.; Oort, F.V.; Frenken, K.; Van Oort, F. Innovation, spillovers and university-industry collaboration: an extended knowledge production function approach. J. Econ. Geogr. 2009, 10, 231-255. [CrossRef]

4. Bathelt, H. Geographies of production: growth regimes in spatial perspective 1-innovation, institutions and social systems. Prog. Hum. Geogr. 2003, 27, 763-778. [CrossRef]

5. Mohnen, P.; Hall, B.H. Innovation and productivity: an update. Eurasian Bus. Rev. 2013, 3, 47-65.

6. Lewis, M.A. Lean production and sustainable competitive advantage. Int. J. Oper. Prod. Manag. 2000, 20, 959-978. [CrossRef]

7. Ngo, L.V.; O'Cass, A. Innovation and business success: The mediating role of customer participation. J. Bus. Res. 2013, 66, 1134-1142. [CrossRef]

8. Roper, S.; Du, J.; Love, J.H. Modelling the innovation value chain. Res. Policy 2008, 37, 961-977. [CrossRef]

9. Mairesse, J.; Mohnen, P. Using Innovation Surveys for Econometric Analysis. Handb. Econ. Innov. 2010, 2, 1129-1155.

10. Stryjakiewicz, T.; Męczyński, M.; Stachowiak, K. Role of Creative Industries in the Post-Socialist Urban Transformation. Quaest. Geogr. 2014, 33, 19-35. [CrossRef]

11. Schumpeter, J.A. Essays: On Entrepreneurs, Innovations, Business Cycles and the Evolution of Capitalism; Taylor \& Francis Group: London, UK, 2017.

12. Drucker, P.F. Managing Oneself. Harvard Bus. Rev. 2005, 1, 100-109.

13. Love, J.H.; Roper, S. Organizing the Innovation Process: Complementarities in Innovation Networking. Ind. Innov. 2009, 16, 273-290. [CrossRef]

14. Klingenberg, B.; Timberlake, R.; Geurts, T.G.; Brown, R.J. The relationship of operational innovation and financial performance-A critical perspective. Int. J. Prod. Econ. 2013, 142, 317-323. [CrossRef]

15. Dorenbosch, L.; Van Engen, M.L.; Verhagen, M. On-the-job Innovation: The Impact of Job Design and Human Resource Management through Production Ownership. Creat. Innov. Manag. 2005, 14, 129-141. [CrossRef]

16. Veza, I.; Mladineo, M.; Gjeldum, N. Managing Innovative Production Network of Smart Factories. IFAC-PapersOnLine 2015, 48, 555-560. [CrossRef]

17. Furman, J.L.; E Porter, M.; Stern, S. The determinants of national innovative capacity. Res. Policy 2002, 31, 899-933. [CrossRef]

18. Peri, G. Determinants of Knowledge Flows and Their Effect on Innovation. Rev. Econ. Stat. 2005, 87, 308-322. [CrossRef]

19. Aguado, S.; Álvarez, R.; Domingo, R. Model of efficient and sustainable improvements in a lean production system through processes of environmental innovation. J. Clean. Prod. 2013, 47, 141-148. [CrossRef]

20. Miciuła, I. Methods of Creating Innovation Indices Versus Determinants of Their Values. Eurasian Economic Perspectives. Eurasian Stud. Bus. Econ. 2018, 8, 357-366.

21. Giuseppe, I.; Szopik-Depczyńska, K.; Stajniak, M.; Konecka, S. Supply chain and innovation activity in transport related enterprises in Eastern Poland. LogForum 2016, 12, 227-236.

22. Capel, C. Mindfulness, indigenous knowledge, indigenous innovations and entrepreneurship. J. Res. Mark. Entrep. 2014, 16, 63-83. [CrossRef]

23. Choi, Y.S.; Lim, U. Contextual Factors Affecting the Innovation Performance of Manufacturing SMEs in Korea: A Structural Equation Modeling Approach. Sustainability 2017, 9, 1193. [CrossRef]

24. Choi, M.J.; Kim, S.; Park, H. Empirical Study on the Factors Influencing Process Innovation When Adopting Intelligent Robots at Small- and Medium-Sized Enterprises-The Role of Organizational Supports. Information 2018, 9, 315. [CrossRef]

25. Galindo, M.-A.; Méndez, M.T. Entrepreneurship, economic growth, and innovation: Are feedback effects at work? J. Bus. Res. 2014, 67, 825-829. [CrossRef] 
26. Zhao, F. Exploring the synergy between entrepreneurship and innovation. Int. J. Entrep. Behav. Res. 2005, 11, 25-41. [CrossRef]

27. Zwolak, J. THE EFFECTIVENESS OF INNOVATION PROJECTS IN POLISH INDUSTRY. Rev. Innov. Compet. 2016, 2, 97-110. [CrossRef]

28. Kraus, S.; Richter, C.; Brem, A.; Cheng, C.-F.; Chang, M.-L. Strategies for reward-based crowdfunding campaigns. J. Innov. Knowl. 2016, 1, 13-23. [CrossRef]

29. Miciuła, I. Financial innovations on the currency market as new instruments to risk management. J. Int. Stud. 2015, 8, 138-149. [CrossRef]

30. Garcia, S.; Luis, J.; Perez-Ruiz, S. Development of capabilities from the innovation of the perspective of poverty and disability. J. Innov. Knowl. 2017, 2, 74-86. [CrossRef]

31. Szopik-Depczyńska, K. Effects of Innovation Activity in Industrial Enterprises in Eastern Poland. Oeconomia Copernic. 2015, 6, 53. [CrossRef]

32. Mitek, A.; Miciuła, I. Determinants of Functioning of Private Enterprises and Barriers to Their Development. Transylv. Rev. 2017, 1, 123-139.

33. Brzozowska, A.; Kabus, J. Determinants of Enterprises' Innovativeness in the Light of Empirical Studies Case Studies of Austria and Poland, Scientific Notebooks of the Silesian University of Technology. Organ. Manag. 2018, 116, 7-22.

(C) 2019 by the authors. Licensee MDPI, Basel, Switzerland. This article is an open access article distributed under the terms and conditions of the Creative Commons Attribution (CC BY) license (http://creativecommons.org/licenses/by/4.0/). 